\title{
1 Large-Scale Controlled Experiment Demonstrates 2 Effectiveness of Methane Leak Detection and Repair 3 Programs at Oil and Gas Facilities
}

4

Jiayang (Lyra) Wang ${ }^{1 *}$, Brenna Barlow ${ }^{2}$, Wes Funk ${ }^{3}$, Cooper Robinson ${ }^{2}$, Adam Brandt ${ }^{4}$, and Arvind P. Ravikumar ${ }^{5}$

${ }^{1}$ Department of Data Science, Harrisburg University of Science and Technology, Harrisburg PA 17101

${ }^{2}$ Radicle, Calgary, AB T2P 3C5

${ }^{3}$ DXD Consulting Inc., Calgary, AB T2P 0S5

${ }^{4}$ Department of Energy Resources Engineering, Stanford University, Stanford CA 94305

${ }^{5}$ Department of Petroleum and Geosystems Engineering, The University of Texas at Austin, Austin TX 78712

Corresponding author: Arvind P. Ravikumar

Email: arvind.ravikumar@austin.utexas.edu

Keywords: Methane emissions, LDAR survey, Oil and gas, Policy effectiveness

\section{Abstract}

The importance of reducing methane emissions from oil and gas operations as a nearterm climate action is widely recognized. Most jurisdictions around the globe using leak detection and repair (LDAR) programs to find and fix methane leaks. In this work, we empirically evaluate the efficacy of LDAR programs using a large-scale, bottom-up, randomized controlled field experiment across $\sim 200$ oil and gas sites in Canada. We find that tanks are the single largest source of emissions, contributing to nearly $60 \%$ of total emissions. The average number of leaks at treatment sites that underwent repair reduced by $\sim 50 \%$ compared to control sites. Although control sites did not see a reduction in the number of leaks, emissions reduced by approximately $36 \%$ suggesting potential impact of routine maintenance activities to find and fix large leaks. By tracking tags on leaking equipment over time, we find a high degree of persistence - leaks that are repaired remain fixed in follow-up surveys, while non-repaired leaks remain emitting. We did not observe any significant growth in emission rate for non-repaired leaks, suggesting that any increase in observed leak emissions following LDAR surveys are likely from new leaks. Vent emissions reduced by $38 \%$ without a significant reduction in the average number of vents across control and treatment sites, showing the importance of both anomalous vents and temporal variations in vent emissions. Our results show that a focus on equipment and sites that are prone to high emissions such as tanks and oil sites are key to cost-effective mitigation. 


\section{Introduction}

Methane $\left(\mathrm{CH}_{4}\right)$ is a short-lived but highly potent greenhouse gas (GHG) with a global warming potential (GWP) 28 times that of carbon dioxide $\left(\mathrm{CO}_{2}\right)$ over 100 years [1]. If global energy sector methane emissions were its own country, it would be the third largest emitter in the world, behind only China and the US. The recently concluded $26^{\text {th }}$ Conference of Parties saw over 100 countries pledging to reduce methane emissions by $30 \%$ by 2030 [2]. In particular, emissions from oil and gas (O\&G) operations contribute to $14 \%$ of all methane emissions globally [3], [4]. Most jurisdictions around the world use periodic leak detection and repair (LDAR) surveys to find and fix methane leaks in the O\&G sector [5], [6].

Studies across Canada and the U.S. have consistently demonstrated significant underestimation of methane emissions in official GHG inventories [7]-[11]. In the Red Deer region in Alberta, recent studies have found measured emissions to be $15-18$ times higher than those directly reported to the Alberta Energy Regulator's (AER) [12], [13]. This discrepancy is attributed to incomplete reporting requirements and the heavy-tailed emission distribution commonly observed across oil and gas facilities [7], [8], [13]-[17]. These high-emitters have significant spatiotemporal uncertainty, creating challenges to their timely detection both for estimating accurate emissions inventory and mitigation efforts [18]-[21].

Detailed component-level emissions data can improve our understanding of the characteristics and distribution of emission sources. However, collecting such data can be time-consuming and labor intensive. Large-scale studies of methane emissions from the upstream of the oil and gas sector are typically done at the site-level through aircraft and mobile laboratory measurements, or at the regional level using mass-balance approaches [12], [13], [22], [23]. Though such methods can survey a large number of sites in a short time, they have higher detection limits and cannot directly identify emission sources [24]. As a result, these studies seldom offer insights into emitting components or the root-cause of emissions [25]. Yet, an analysis of the time evolution of methane emissions requires component-level data to determine persistence, mean time to failure, and other critical parameters that affect methane emissions. Furthermore, top-down aerial methods cannot differentiate emissions between leaks and vents. In our definition, leaks are nonoperational and unintentional, whereas vents are operational and intentional. Since an LDAR program aims to reduce leaks, detailed data on leaks and vents can help estimate the effectiveness of the program.

Most field studies of methane emissions from oil and gas facilities using new technologies such as aircraft and satellite provide 'snap-shot' measurement data - while detailed in spatial extent, they do not shed light on temporal variations in emissions [12], [26]. This is critical as recent measurements have observed significant differences in emissions across seasons, time of day, and other temporal variables [27], [28]. Furthermore, only one recent study has empirically demonstrated emissions reductions from regulatory LDAR programs with data from a small number of facilities [29]. 
In this work, we present results from a large-scale, randomized controlled trial of the effectiveness of LDAR surveys in reducing methane emissions using component-level, repeat surveys from approximately 200 oil and gas sites across 18 operators in Alberta, Canada. This work brings together several critical aspects of methane emissions for the first time to shed light on the temporal evolution of emissions under LDAR programs. First, random site selection without the knowledge of the operators involved avoids the 'coalition of the willing' challenge associated with bottom-up, component-level studies that typically require operator consent for site access. Second, the large sample size for a component-level randomized study ensures representativeness of oil and gas facilities and therefore, broad applicability of insights. Third, differentiating control and treatment sites allows differentiation of emissions reductions associated with voluntary inspection and maintenance activities from that of an LDAR program. Fourth, emissions tracking through repeat surveys over the course of 12 months provides the first scientific data on emissions growth rate, persistence of leaks, and the effectiveness of the repair process. Findings from our study will answer long-standing scientific questions on methane emissions as well as help regulators identify the most effective emissions mitigation policies.

\section{Materials and Methods}

Site Selection: Sites were selected from publicly available data on operating oil and gas upstream facilities from Canada's Petroleum Information Network (Petrinex) [30]. Because the study is designed to be randomized and anonymized, no operator was consulted during the site selection process. Site access was guaranteed by the Alberta Energy Regulator (AER) that deputized the field crew to conduct LDAR surveys. Deputization provided the field crew with the same freedom of access provided to the AER under provincial legislation. This further allowed the study to avoid the 'coalition of the willing' challenge often observed in component-level methane emissions studies where operator consent is often required for site access and ground-based surveys. However, the field crew did not encounter any opposition from operators and did not have to use the AER deputization to access sites for measurements. Some selected sites were not surveyed due to various operational and environmental conditions, such as road conditions or ongoing maintenance work.

We selected 204 sites across a $50 \mathrm{~km}$ x $50 \mathrm{~km}$ region within the Red Deer production area. The Red Deer region is in Central Alberta and is characterized by natural gas and light oil production. The representativeness of the distribution of site types in the study sample to the Red Deer production region was verified using 2-sample KolmogorovSmirnov test (see SI section S.1.1). Five major site types were included in the study sample - gas single well battery (Gas SW), gas multiwell group battery (Gas MW), crude oil single-well battery (Oil SW), crude oil multiwell group battery (Oil MW), and crude oil multiwell proration battery (Oil MWPro) (see SI section S.1.2) [31]. The number of sites selected for each site type is representative of the distribution in the Red Deer region. Next, selected sites were divided into four groups based on the number of LDAR surveys that would be conducted over the course of one year: (1) control sites where 
operators will not be informed about emission sources, and treatment sites that are visited (2) annually, (3) biannually, or (4) tri-annually where operators will be informed about emission sources and asked to undertake repair activities. The initial benchmark survey for all control and treatment sites was conducted from August to October 2018. The final survey was conducted in fall 2019 from August to October on all control and treatment sites. Annual sites and control sites were only visited in the initial and final surveys. Biannual sites underwent intermediate LDAR survey in March 2019. Tri-annual sites underwent intermediate surveys in November 2018 and May 2019. Sites that were not able to be consistently visited on schedule -- either because of a change in status of a site (for example, shut-in during the study period) or weather conditions -- were removed from our analysis (see SI section S.1.2 for detailed breakdown).

Field Survey Methodology: Davis Safety Consulting Ltd. (henceforth 'field crew') were contracted to conduct all ground based LDAR surveys in this study because of their prior experience in collecting research-quality data [29]. The field crew were trained in the use of FLIR GF-320 OGI camera and the Providence Photonics' QL320 quantitative OGI tablet (QOGI) for methane emissions detection and quantification, respectively [32], [33]. The GF-320 is the industry standard in LDAR surveys across North America [34], [35]. QOGI was selected over the conventional Bacharach Hi-Flow sampler because: 1) QOGI is able to quantify all emissions whereas Hi-Flow Sampler can only estimate emissions that are accessible and safe; 2) QOGI has a wider range of measurement capabilities while Hi-Flow Sampler is limited by the maximum displacement of the blower; and 3) QOGI avoids recent challenges associated with Hi-Flow Sampler around gas composition, sensor transition failure, and calibration that could underestimate emissions [36]-[39]. Despite our efforts and precautions to generate reasonable emission quantifications, the accuracy of QOGI and other image-based detection technologies fundamentally relies on plume detection algorithms that distinguish plume pixels from non-plume pixels on the OGI camera. A recent controlled release study found that the QOGI technology has a high accuracy when interpreted in an aggregated context, with a bootstrapped error of $+26 \% /-23 \%$ from a sample size of 50 emissions, similar to those observed from Bacharach Hi-Flow samplers [40]. However, individual quantification estimates can have higher uncertainties.

The site visit process is as follows: one member of the field crew examines each component and equipment with the infrared camera for emissions, both leaks and vents. A second member of the crew records meta data on every emission and attaches a physical tag to a leak, if necessary. Tags are noted with unique identification numbers and are only used for leak emissions that are safe to access at treatment sites. No tags are used at control sites to allow comparison of performance against treatment sites where repairs are conducted. In contrast, at treatment sites that were visited at annual, bi-annual, and tri-annual survey frequency, the field crew notified the operators of the emissions found on sites for subsequent repair after each survey, with the understanding that the field crew may return to conduct a post-repair LDAR survey. Although operators of control sites were not informed of the emissions found by the field crew (with exceptions for safety), they were also not explicitly asked to not conduct repairs, so emissions change at control sites over the course of the year can be considered a proxy for voluntary inspection and maintenance activities. 
In contrast to regulatory LDAR surveys, the field crews were instructed to detect and measure all methane emissions at sites, including permitted vent emissions that will not undergo repair process. This was done for two reasons. One, measuring all emissions provided critical insights into the relative importance of leaks and vents in methane mitigation that is often not available in the literature. Two, it provided a more nuanced understanding of the source of large emissions observed at oil and gas facilities.

Data Collection: When an emission was detected, the field crew would find an appropriate angle to take several videos using a tripod mounted FLIR GF320 to visualize and quantify the emission. The field crew would also measure the imaging distance with a range finder and determine the windspeed and temperature using an anemometer. In addition, the field crew would record an image and a 15 30 second video of every emission found on site to assist operators with the repair process and generate a record for every detected emission.

In addition to quantitative data on methane emissions, the field crew also collected other ancillary data on site to assist with analysis and interpretation. At the site level, the field crew collected data on operator name, site name, legal subdivisions (LSDs), production type, and major equipment count. At the component level, the field crew recorded a detailed description of the emission including its location, emitting component, equipment, and whether the emission was a leak (unintentional emissions, also referred to as "fugitive emissions") or a vent (intentional emissions). While definitions vary across jurisdictions, emissions were categorized as leaks if they were a result of component malfunction or emissions from equipment with control devices. Vents, on the other hand, included pneumatic devices in normal operation, open-ended lines, abnormal emissions from vent sources (e.g., open thief hatch from an uncontrolled tank battery), and other equipment that emit methane by design.

Data Analysis: All emissions were mapped into six major component categories [35], [41]: flange/connector, open-ended line (disaggregated into tank and non-tank), pneumatics, tank level indicator, thief hatch, and valves. There are two scenarios in which emissions could not be quantified using the QOGI system. In the first scenario, the emission size was too small for the QOGI system to quantify. Here, we assigned an emissions rate corresponding to the lowest measured emission rate for that component type in that survey. $0.6 \%$ of the emitters were assigned an emission rate using this method. In the second scenario, the emission was not quantifiable due to unfavorable atmospheric conditions or interference from nearby emissions. Here, we assigned an emission rate corresponding to the average emission rate from the emitting componenttype in that survey. $4 \%$ of the emitters were assigned emission rates using this method (see SI section S.1.4). All emissions are reported in mass flow rates, with an average volume weighted methane content in natural gas of 0.82 representative of the Red Deer region (see SI section S.1.3) [11].

To derive proportional loss rates (PLR), we retrieved monthly production data for each site from Petrinex [30] and correlated these with the corresponding QOGI survey months. 
222 Because the Red Deer region includes production of both oil and gas, we used an energy-

223 based allocation method to calculate PLR $\mathrm{R}_{\mathrm{e}}$ as shown in Equation (1) [29]. The SI

\section{Results}

We selected approximately 200 representative sites in the Red Deer region of Alberta and divided into four groups - three treatment groups and one control group. The three treatment groups, with approximately 45 sites each, were surveyed annual, bi-annually, and tri-annually, respectively. The sites in the control group were surveyed annually. Surveys were conducted using optical gas imaging technology, recording all methane emissions on site include vents. Emissions are quantified using quantitative optical gas imaging technology (see Methods and SI section S.1).

At each treatment site, the results of the LDAR survey were provided to the site operator, with the expectation that repairs would be conducted prior to the next survey on that site. At control sites, the operator was not notified about the results of the LDAR surveys but were free to undertaken routine maintenance activities. The initial baseline survey of all sites was conducted in fall 2018 and the final survey was conducted a year later, in fall 2019 (see SI section S.1.2).

\section{Vent emissions, on average, constitute a disproportionate share $(>69 \%)$ of total methane emissions.}

Figure 1 compares component-level emissions data between the initial and final surveys in fall 2018 and fall 2019, respectively. Figure 1(a) and Figure 1(b) show the cumulative distribution of component-level emissions as a function of rank-ordered cumulative number of emitters. Emitters are disaggregated by six major component types as well as by leak and vent emissions. We found 1025 emitters in the initial survey in 2018 and 1004 emitters in the final survey in 2019. The average emission rate reduces by $41 \%$ from $49 \mathrm{~kg}$ $\mathrm{CH}_{4} / \mathrm{d}\left(95 \% \mathrm{CI}\left[41\right.\right.$ - 62]) to $29 \mathrm{~kg} \mathrm{CH}_{4} / \mathrm{d}$ (95\% CI [24 - 38]). The decrease in average emission rate can be attributed to reduction in the number of large emitters. In 2018, there are 94 large emitters emitting $>100 \mathrm{~kg} \mathrm{CH}_{4} / \mathrm{d}$, contributing to $74 \%$ of total emissions. In 2019, the number of large emitters emitting $>100 \mathrm{~kg} \mathrm{CH} / \mathrm{d}$ drops to 65 emitters, contributing to $62 \%$ of total emissions. In addition, $90 \%$ of the emissions come from components emitting $>31 \mathrm{~kg} \mathrm{CH}_{4} / \mathrm{d}$ in 2018 and $>16 \mathrm{~kg} \mathrm{CH}_{4} / \mathrm{d}$ in 2019 - these correspond to only $22 \%$ and $27 \%$ of emitters in 2018 and 2019 , respectively. Such skewed componentlevel emissions distribution have been observed in several recent studies [13], [17], [42]. Overall, the highest-emitting $5 \%$ of emitters contribute to $56 \%$ of total emissions in 2019 , compared to $62 \%$ in 2018. Among the top 5\% of emitters in $2018(n=51)$, the most common emitting component is a tank related open-ended line $(n=22)$, contributing to $30 \%$ of total emissions. The distribution is similar in $2019-$ tank related open-ended lines 

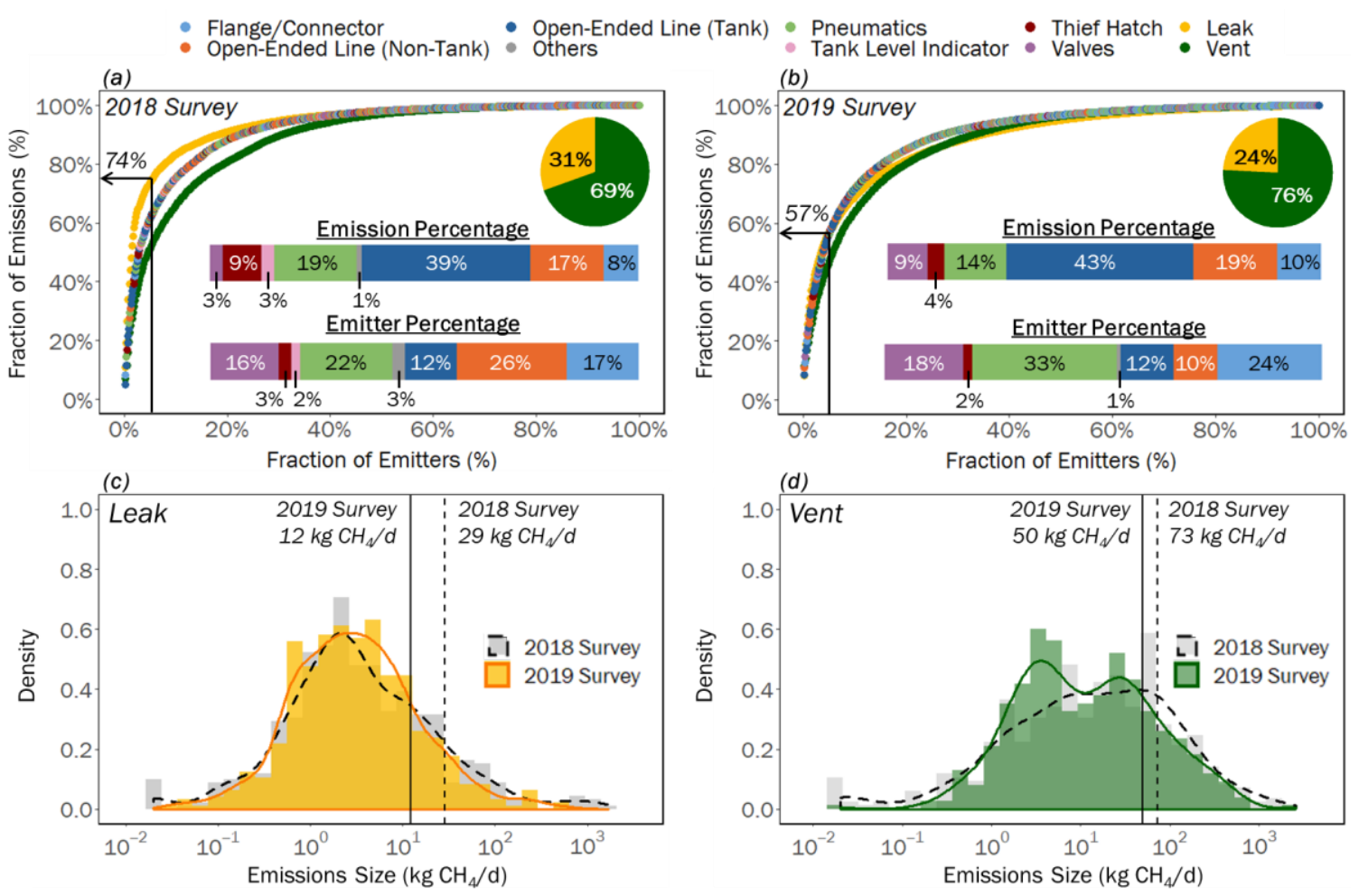

267

268

269

270

271

272

273

274

275

276

277

278

279

280

281

282

283

284

285

286

287

288

289

Figure 1. Component-level emissions comparison between 2018 survey and 2019 survey. Figure 1(a) and Figure 1(b) show the cumulative distribution of emissions as a function of rank-ordered cumulative number of emitters disaggregated by six major components, and emission type (leak and vent). The inset bars show the fractional make-up of emissions and emitters by components. The inset pie charts show the emissions breakdown between leak (yellow) and vent (green). Figure 1(c) and Figure 1(d) show the distributions of leak and vent emissions during the initial survey in August 2018 (grey) and the final survey in August 2019 (yellow, leaks and green, vents) in log scale. The solid vertical lines represent average emissions rates in the 2019 survey and the dashed vertical lines represent average emissions rates in 2018 survey.

The inset bars in Figure 1(a) and Figure 1(b) show the fractional make-up of emitters and emissions across major component types. Flange/connector, pneumatics, and valves are the most common emitting components, accounting for nearly $75 \%$ of all emitters. However, they only contribute to $33 \%$ of total emissions in 2019 . On the other hand, components such as thief hatch and tank related open-ended line, despite accounting for only $14 \%$ of total emitters, are responsible for $47 \%$ of total emissions in 2019. Overall, tank related emissions - both leaks and vents - together contribute a significant fraction of total methane emissions (58\%) and represent opportunities for specific monitoring and mitigation action.

The inset pie charts show the relative contributions of leaks and vents to total emissions. 
Vents (including anomalous vents) contribute to the majority of total emissions $-69 \%$ in 2018 and $76 \%$ in 2019. The increase in contribution from vents in 2019 is a result of mitigation actions taken to reduce leaks between 2018 and 2019. Total emissions reduced by $42 \%$ between 2018 and 2019 . Disaggregating between leaks and vents, we find that here show that vents are a significant contributor to total emissions that are not directly addressed by LDAR programs. However, LDAR programs help bring anomalous vents to the attention of the operator potentially increasing their effectiveness beyond conventional leak mitigation efforts.

Figures 1(c) and Figure 1(d) compare the changes in emission-size distribution of leaks and vents between 2018 and 2019. There are 541 leaks in 2018 and 568 leaks in 2019. Even though the number of leaks found in the two surveys are similar, the average leak emission rate decreases by 59\%, from $29 \mathrm{~kg} \mathrm{CH} / \mathrm{d}$ in 2018 (95\% CI [20 - 43]) to $12 \mathrm{~kg} \mathrm{CH}_{4} / \mathrm{d}$ in 2019 (95\% CI [10 - 17]). The decrease is mainly due to the reductions from high-emitting leaks associated with repair activities - there are 22 leaks that emit $>100 \mathrm{~kg} \mathrm{CH}_{4} / \mathrm{d}$ and contribute to $71 \%$ of total leak emissions in 2018 . By comparison, there are only 12 leaks emitting over $100 \mathrm{~kg} \mathrm{CH}_{4} / \mathrm{d}$, contributing to $42 \%$ of total leak emissions in 2019 . Total leak emissions from these large emitters reduced by $73 \%$ between surveys. As a result, the contribution of the top 5\% of leaks to total leak emissions drops from $74 \%$ in 2018 to $57 \%$ in 2019 (Figure 1(a) and Figure 1(b)).

There are 484 vents in 2018 and 436 vents in 2019 . While the counts of vents decrease by $10 \%$ between surveys, the average vent emissions rate decreases by $32 \%$, from $73 \mathrm{~kg} \mathrm{CH}_{4} / \mathrm{d}$ (95\% CI [58 - 96]) in 2018 to $50 \mathrm{~kg} \mathrm{CH}_{4} / \mathrm{d}(95 \%$ CI [40 - 71]) in 2019. Similar to leaks, reduction in vent emissions mainly come from large emitters. The number of vents that emit $>100 \mathrm{~kg} \mathrm{CH}_{4} / \mathrm{d}$ decreases from 72 to 53 with corresponding emissions reduction of $43 \%$. Although we cannot attribute reduction in vent emissions to any operator-specific action, we hypothesize several potential causes: 1) some vents are anomalous and are fixed by operators as part of routine maintenance; and 2) some vents are episodic and thus, not detected during the fall 2019 visit, or 3) some vents were addressed with process changes, equipment improvement, or targeted removal due to notification in LDAR campaign. Leaker emission factors across the six component types and five surveys are provided as tables in the supplementary information (see SI section S2).

\section{Tanks are the single largest source of methane emissions, contributing to $58 \%$ of total emissions in 2019.}

Figure 2 shows the distribution of emissions by major component types and tank relation in 2018 and 2019. Across all components, average emissions reduce between $35 \%$ and 84\% from 2018 to 2019. Even though the average emission from non-tank related openended line increases from $32 \mathrm{~kg} \mathrm{CH}_{4} / \mathrm{d}\left(95 \%\right.$ CI [25 - 47]) to $53 \mathrm{~kg} \mathrm{CH}_{4} / \mathrm{d}(95 \% \mathrm{CI}$ [36 $78]$ ), both the count of emitters and total emissions reduce by $61 \%$ and $37 \%$, respectively. The highest-emitting component types are found on tanks - thief hatch and tank related open-ended lines, with an average emission rate of $80 \mathrm{~kg} \mathrm{CH}_{4} / \mathrm{d}(95 \% \mathrm{CI}$ [45 - 138]) and $104 \mathrm{~kg} \mathrm{CH}_{4} / \mathrm{d}$ (95\% CI [77 - 185]), respectively, in 2019. 
336 Pneumatic devices, typically considered outside the scope of LDAR programs, emit $12 \mathrm{~kg}$ $337 \mathrm{CH}_{4} / \mathrm{d}(95 \% \mathrm{CI}[11-15])$ on average in 2019, which represents a significant reduction 338 from $44 \mathrm{~kg} \mathrm{CH}_{4} / \mathrm{d}(95 \% \mathrm{CI}$ [29 - 73]) in 2018. The reduction in average emissions is driven 339 by reduction from large emitters $\left(>100 \mathrm{~kg} \mathrm{CH}_{4} / \mathrm{d}\right)$. The number of pneumatic devices that 340 emits $>100 \mathrm{~kg} \mathrm{CH}_{4} / \mathrm{d}$ decreases from 19 in 2018 to 4 in 2019 and their emissions reduced 341 by $91 \%$. Flanges and valves represent some of the most common component types that are 342 prone to exhibit leaks from wear and tear or component failure, but do not contribute 343 significantly to overall emissions. On average, flanges and valves emit $12 \mathrm{~kg} \mathrm{CH} 4 / \mathrm{d}(95 \%$ $344 \mathrm{CI}[7-22])$ and $14 \mathrm{~kg} \mathrm{CH}_{4} / \mathrm{d}(95 \% \mathrm{CI}$ [8 - 27]), respectively. The contrast in average 345 emission rate between high-emitting but relatively uncommon components and low346 emitting but common components suggest potential opportunities in mitigation protocols 347 that focus on sources most likely to exhibit high emissions.

Aggregating all tank related emissions across component types, we find that tanks 350 contribute to $52 \%$ and $58 \%$ of total emissions in 2018 and 2019 , respectively, despite only 351 comprising $18 \%$ and $16 \%$ of total emitters. The disproportionate contribution from tanks 352 is consistent with findings from recent studies and makes it a potential target for focused 353 mitigation opportunities [27], [43], [44]. Furthermore, the average emission rate of tank354 related emissions in 2019 is $105 \mathrm{~kg} \mathrm{CH}_{4} / \mathrm{d}$ (95\% CI [81 - 165]), which is nearly an order of 355 magnitude (7.5x) larger than the average emission rate from non-tank related emissions, $35614 \mathrm{~kg} \mathrm{CH}_{4} / \mathrm{d}$. Thus, detecting tank related emissions could likely be accomplished with 357 technologies with higher leak detection thresholds compared to conventional OGI cameras, 358 like remote sensing, fly-by, or drive-by surveys [45]. 

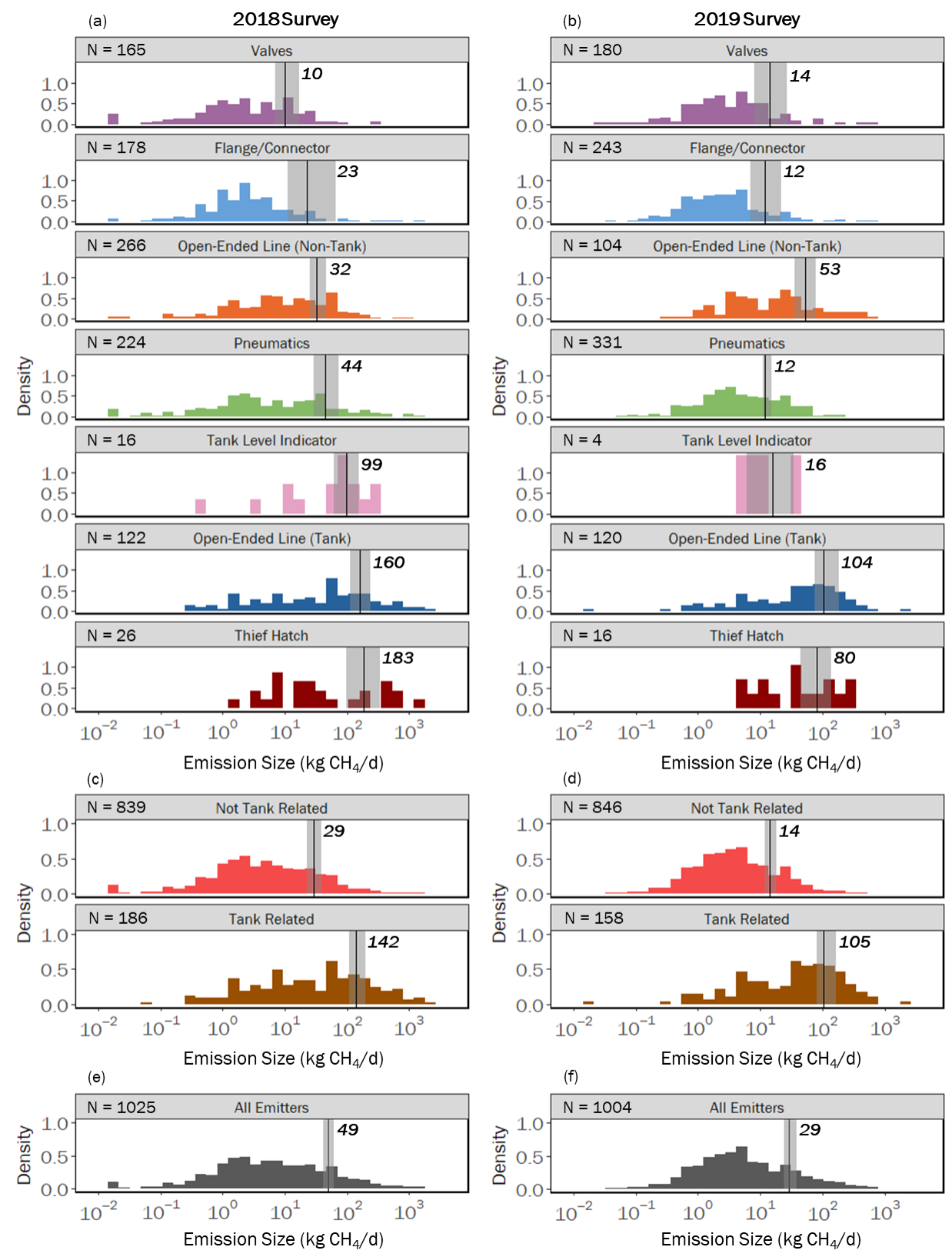

360

Figure 2. Distribution of emissions in log scale disaggregated across six major component types - valves (purple), flange/connector (light blue), open-ended line (non-tank) (orange), pneumatics (green), tank-level indicator (pink), open-ended line (tank) (dark blue), thief hatch (maroon) - and whether they are associated with tanks (hot pink) or not (brown). The solid vertical lines and the bolded numbers next to the lines represent average emissions rates. The gray shaded areas represent $95 \%$ confidence intervals with bootstrapping. The " $N$ " on the top left of each box indicates the sample size. Figure 2(a) and 2(b) present emissions distribution by major component types. Figure 2(c) and 2(d) present emissions distribution by tank relation. Figure 2(e) and 2(f) present emissions distribution across all emitters. 
Emissions from oil sites and multi-well batteries, on average, are more than two times that of emissions from gas sites and single-well batteries, respectively.

Figure 3 summarizes site-level emissions across 148 oil and gas production sites that are measured on schedule (see SI section S.1.2). Average emissions at each site are disaggregated by leaks and vents, and further analyzed based on site type, production, and size. The designation of oil and gas sites are based on established definitions of the oil and gas facilities by the AER. In the 2018 survey, 21 sites do not have any emissions and another 27 sites only have vent emissions, which translates into $32 \%$ of total sites surveyed with no leak emissions. The percentage drops to $25 \%$ in 2019 survey with 9 zero-emission sites and another 28 vent-only sites. Compared to other site-level survey methods such as mobile ground labs and aircraft systems used in prior studies, the OGI technology has a lower detection threshold [25], [45]. This may explain why the percentage of non-emitting 383 sites in our study is lower than that of recent site-level measurements in the US and Canada [22], [24].

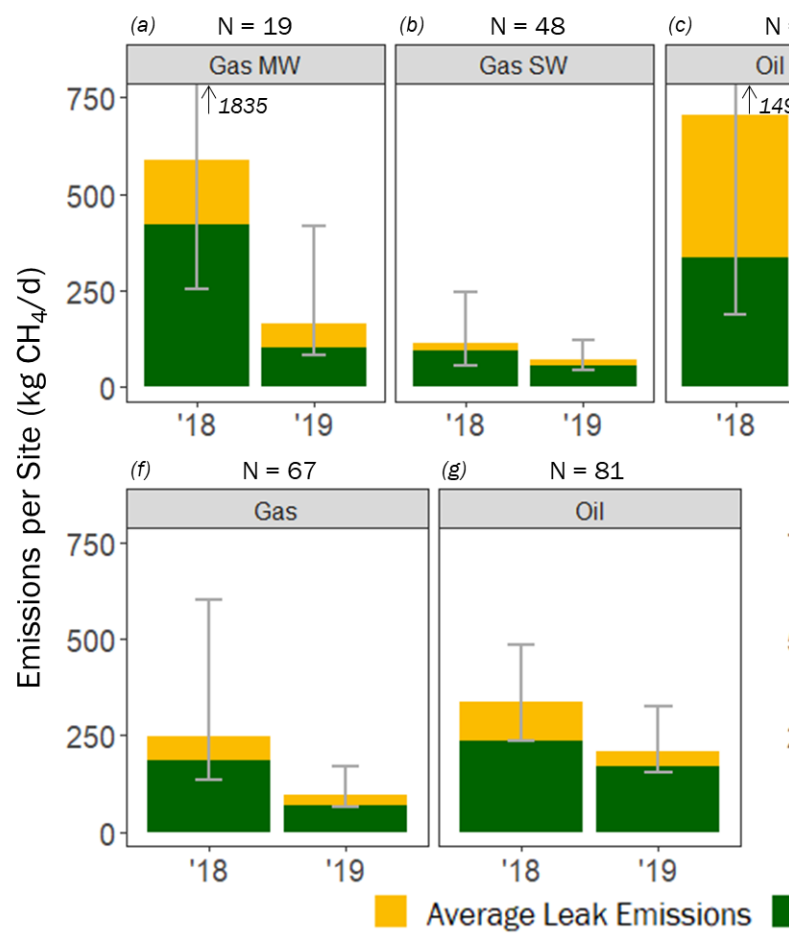

Figure 3. Average leak and vent emissions across the five major site types in 2018 and 2019. Emissions are disaggregated by leaks (yellow) and vents (green) for each site type (Gas MW-gas multiwell group battery, Gas SW-gas single well battery, Oil MWcrude oil multiwell group battery, Oil MWPro - crude oil multiwell proration battery, Oil SW-crude oil single-well battery, Gas-gas production sites, Oil-oil production sites, $S W$ - single well battery, $M W$ - multiwell battery). The numbers on the top correspond to the sample size in each category. Error bars represent $95 \%$ bootstrapped confidence interval of the mean site-level emissions. Average site level emissions are disaggregated by site type (a-e), by gas or oil production $(f-g)$, and by single or multi-well sites $(h-i)$. The numbers next to the arrows on (a), (c), and (i) represent the upper bound of the 


\section{confidence intervals.}

In 2019, the top 5\% of sites contribute to $35 \%$ of total emissions, emitting at least $595 \mathrm{~kg}$ $\mathrm{CH}_{4} / \mathrm{d}$. $90 \%$ of total emissions come from sites emitting $>87 \mathrm{~kg} \mathrm{CH}_{4} / \mathrm{d}$. The average sitelevel emission reduces by $46 \%$ from $295 \mathrm{~kg} \mathrm{CH}_{4} / \mathrm{d}(95 \% \mathrm{CI}$ [215 - 449]) in 2018 to $158 \mathrm{~kg}$ $\mathrm{CH}_{4} / \mathrm{d}(95 \% \mathrm{CI}[122-227])$ in 2019 . Vent emissions are the major contributor to total emissions for nearly every site type considered in this study. In 2019, vent emissions contribute to $62 \%-87 \%$ of total emissions for each site type. In 2018 , vent emissions contribute to $48 \%$ to $84 \%$ of total emissions for each site type.

We also compare the count of emitters on site. Oil MW and Oil MWPro sites have the most emitters per site - 12.4 (95\% CI [6.5 - 19.3]) and 11.6 (95\% CI [6.5 - 29.0]) respectively in 2019. Oil SW and Gas SW have the fewest emitters per site, 3.9 (95\% CI [3.3 - 4.6]) and 2.9 (95\% CI [2.4 - 3.5]), respectively. The average count of emitters per site of all sites decreases by $9 \%$, from 5.7 (95\% CI [4.8 - 7.2]) in 2018 to $5.2(95 \%$ CI [4.4 - 7.1]) in 2019. Yet, average emissions across all sites decrease by over $40 \%$ between 2018 and 2019, indicating the impact of addressing high emitters on overall emissions reductions. Notably, Gas MW sites have the most significant decrease of 2.7 emitters per site, compared to Gas SW, Oil MW, and Oil SW sites, which all decrease by less than 1 emitter/site. The only site type that sees an increase in the number of emitters is Oil MWPro sites, increasing from 9.9 (95\% CI [5.6 - 20.4]) emitters per site in 2018 to 11.6 (95\% CI [6.5 - 29.0]) emitters per site in 2019. The reduction of count of emitters of each site type depends on both the treatment group the site is in and the corresponding repairing activities from the operators, which is further discussed later.

Emissions also vary significantly by type of resource produced and the size of the facility. In 2018, the average emissions from all oil production sites (Oil SW, Oil MW, and Oil MW Pro) is $336 \mathrm{~kg} \mathrm{CH}_{4} / \mathrm{d}\left(95 \%\right.$ CI [236 - 484]), 36\% more than the $247 \mathrm{~kg} \mathrm{CH}_{4} / \mathrm{d}(95 \%$ CI [134 - 600]) from gas production sites (Gas SW, Gas MW). Even though emissions from both oil and gas production sites reduce in 2019, emissions decrease more at gas production sites: a decrease of $61 \%$ at gas production sites, compared to $38 \%$ at oil production sites. As a result of the different rate of decrease, oil production sites $(210 \mathrm{~kg}$ $\mathrm{CH}_{4} / \mathrm{d}\left(95 \% \mathrm{CI}\left[154\right.\right.$ - 327])) emit 2.2 times that of gas production sites $\left(96 \mathrm{~kg} \mathrm{CH}_{4} / \mathrm{d}(95 \%\right.$ CI [63 - 170])) in 2019. Oil sites emit more than gas sites because they are typically associated with equipment such as tanks that are prone to be high emitters and are the largest single source of emissions in this study. Similarly, we find that multi-well batteries emit more than twice that of single well batteries on average in both surveys, potentially attributable to the complexity and higher activity factors associated with multi-well sites. Emissions from both oil and gas multi-well batteries reduce by $47 \%$ from $475 \mathrm{~kg} \mathrm{CH}_{4} / \mathrm{d}$ (95\% CI [285 - 973]) to $254 \mathrm{~kg} \mathrm{CH}_{4} / \mathrm{d}(95 \% \mathrm{CI}[182$ - 365]). Correspondingly, emissions from both oil and gas single well batteries reduce by $46 \%$ from $219 \mathrm{~kg} \mathrm{CH} 4 / \mathrm{d}(95 \%$ CI [148 - 327]) to $118 \mathrm{~kg} \mathrm{CH}_{4} / \mathrm{d}(95 \% \mathrm{CI}[81$ - 213]).

Gas MW sites see the highest emissions reduction of $72 \%$, followed by Oil SW and Oil MW sites, both reducing by $49 \%$. The decrease in site level emissions is driven by a few sites with large emissions reductions since the initial survey in 2018. For example, the top 
two Gas MW sites with the highest emissions reduction make up $75 \%$ of total emissions reduction across all Gas MW sites. The decrease in emissions mainly come from large emissions associated with tank level controllers and tank open-ended lines (e.g., candy cane vent) in the initial survey, which were not emitting during the final survey. Similarly, the top two Gas SW sites with the highest emissions reduction contribute to $63 \%$ of total emissions reductions across all Gas SW sites. While Oil MW sites have a small sample size that may not be representative of the site type, it follows the same pattern where the top two sites with the highest emissions reduction contribute to $84 \%$ of total emissions reduction across all Oil MW sites. The persistent difference between oil and gas sites in both emissions and the potential for emissions reductions suggest mitigation opportunities for policies that are directed at specific site types.

On a proportional loss rate based on energy production (see Equation (1)), sites emit 2.6\% of total energy produced in 2019, in line with recent findings. For example, Chan et al.'s recent revision of methane emissions estimates from Alberta and Saskatchewan translate to an energy based proportional loss rate of $2.8 \%$ [11]. In general, there are fewer points of comparison with published studies as the typical practice in the literature has been to report on gas-based proportional loss rates (see SI section S.5 for gas-based PLR). The PLR $\mathrm{e}_{\mathrm{e}}$ of oil sites is $3.0 \%$, approximately $60 \%$ more than that of gas sites at $1.9 \%$. The higher PLR at oil sites can be attributed to the higher incidence of tanks and resulting higher emissions (Figure 3). Although MW batteries emit more methane, on average, than SW batteries, their $\mathrm{PLR}_{\mathrm{e}}$ is significantly lower on account of high energy production - the average energy produced from MW batteries is nearly 5 times that of SW batteries. Thus, the PLR $\mathrm{R}_{\mathrm{e}}$ of MW and SW batteries are $1.8 \%$ and $4.1 \%$, respectively. In line with several recent studies, we find a decreasing trend in proportional loss rates as production increases (see SI section S.5) [29].

Emissions comparison across the 18 operators shows significant variation based on asset portfolio. Operators with more oil sites exhibit higher average emissions. Moreover, even though operators have similar median site emissions, the average site emissions vary by an order of magnitude. This discrepancy points to the impact of high-emitting sites on overall emissions and reinforce the importance of finding high-emitting sites quickly for effective emissions mitigation (see SI section S.7).

\section{Time series analysis of surveys demonstrate high degree of repair effectiveness- repaired leaks do not emit in subsequent surveys.}

Figure 4 shows the impact of repair activities on leaks across different components using data from the leak tags attached by the field crew. Tags are not placed on all leaking components because of access or safety restrictions. For tagged leaks that have been repaired, the operator typically includes a 'date of repair' on the tag, which helps the field crew to confirm repair activities during the subsequent survey. In our analysis, we assume that repair activities are the only reason a tagged leak would stop emitting. If left unrepaired, the tagged leak would not stop emitting automatically. There are four scenarios of the state of the leaking component as observed during subsequent surveys. First, the tagged leak was repaired and not emitting during subsequent survey with a 'date of repair' tag. Second, even though the tagged leak did not have a 'date of repair' tag, it was not 
emitting during the follow up survey. We assume that the operators forgot to note the date on the tag after repairing the leak and consider the leak as repaired. Third, it is possible that a tagged leak was emitting during the subsequent survey despite having a 'date of repair' tag. In this case, we assume that the leak recurred. Fourth, for tagged leaks that were emitting at the follow up survey without 'date of repair' tags, there are two possibilities: (a) the leak was not repaired and (b) the leak was repaired and recurred. Without the 'date of repair' on the tags, we were unable to distinguish between the scenarios (a) and (b).

Here, we consider emitters tagged across all five surveys and compare emissions between the survey when the tag was first created ('initial survey') and the survey when the tagged component was re-examined ('follow-up survey'). For example, at tri-annual sites, if a leak was first tagged in the November 2018 survey, the November 2018 survey is considered the "initial" survey and the subsequent May 2019 survey is considered the "follow up" survey. On the other hand, if the emission was first tagged in the August 2018 survey ('initial' survey), the subsequent survey is the November 2018, and is considered the 'follow-up survey'. Only components with more than 20 tagged emissions are included in the analysis to ensure representativeness.

We find that emissions are persistent - leaks that are not repaired were likely to be emitting in the follow-up survey while repaired leaks remained non-emitting. The average leak rate of non-repaired flange/connecter $(n=137)$ stays the same between initial and follow up surveys at $4 \mathrm{~kg} \mathrm{CH} / \mathrm{d}$. Similarly, valves $(\mathrm{n}=103)$ that are not repaired after the initial survey exhibit similar leak rates in the follow-up survey. The increase in pneumatics $(n=60)$ is driven by one large emitter that contribute $87 \%$ of total emissions increase at follow up surveys - without it, the average emission at follow-up surveys decreases to $7 \mathrm{~kg} \mathrm{CH}_{4} / \mathrm{d}$. Thus, leaks that are not repaired do not increase significantly in size during the time between LDAR surveys.

Repairs are highly effective - leaks that are repaired stay fixed and did not recur. Flange/connector $(n=53)$, pneumatics $(n=57)$ and valves $(n=43)$ are all emitting, on average, $<0.5 \mathrm{~kg} \mathrm{CH}_{4} / \mathrm{d}$ after repair. These results are significant in that the confidence intervals of leak rates for repaired emissions in the initial survey and follow-up survey do not overlap, indicating high repair effectiveness (see SI Table S10). As a result, we conclude that any increase in measured emissions in LDAR surveys is likely to come from new leaks rather than an increase in emissions from unrepaired leaks. 

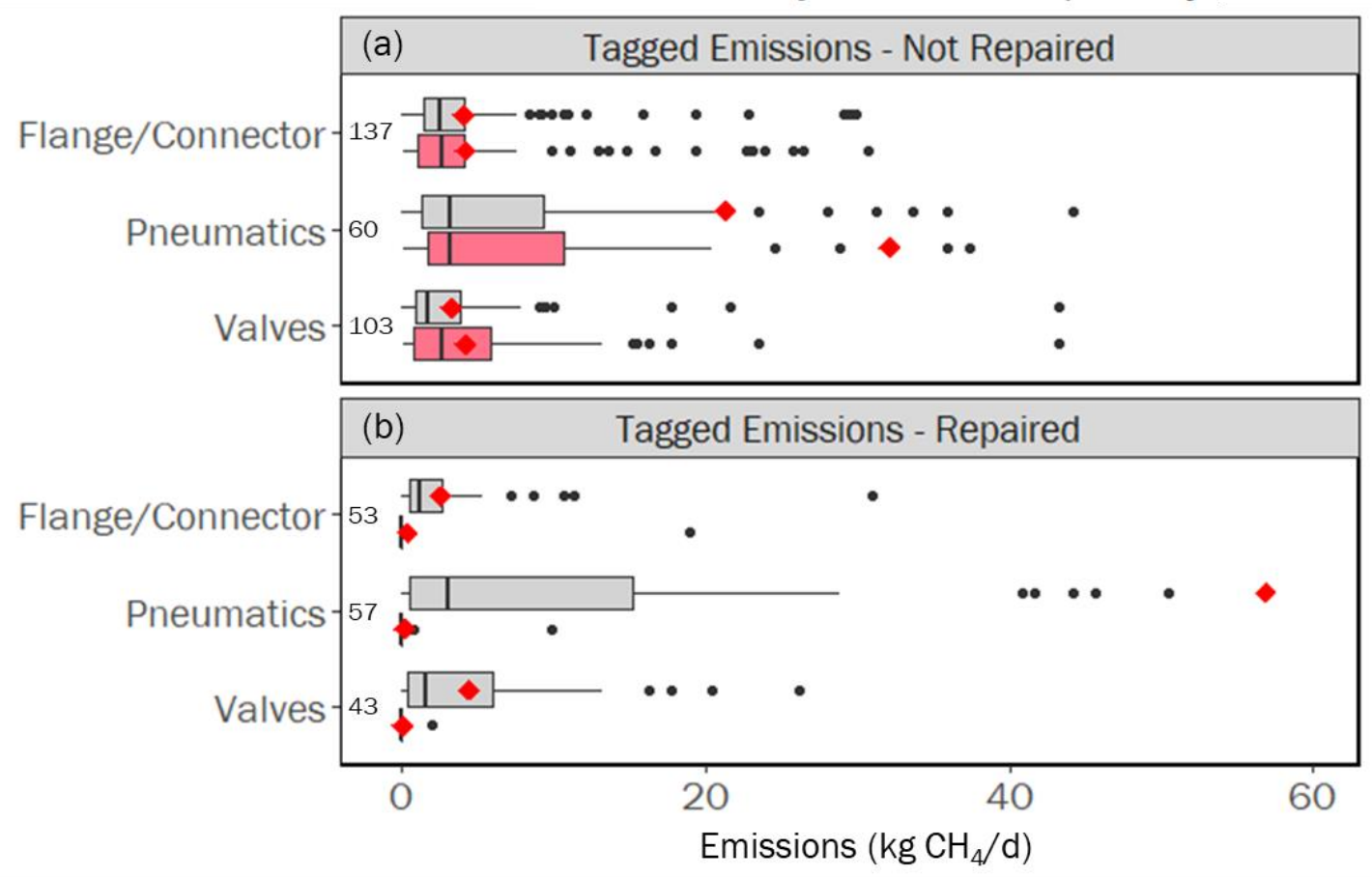

Figure 4. Boxplots showing the distribution of tagged component-level leak emissions at initial and follow-up surveys. Only components with $>20$ tagged leaks are included. The numbers between $y$-axis and the bars represent the sample size for each component-type. The red diamonds show the mean of each category. The black dots are outliers. There are 6 outliers with emissions larger than $60 \mathrm{~kg} \mathrm{CH} / \mathrm{d}$.

LDAR surveys are effective at reducing leak emissions: the average number of leaks at treatment sites are significantly lower than those at control sites, while the average number of vents do not change.

The impact of repairing leaks is further analyzed at the site level between treatment and control sites. In Figure 5, the change in site-level average number of leaks and vents are compared based on repair activities associated with different survey frequencies. A repaired site is defined by examining emissions and operators' notes associated with the tags attached to leaking components by the survey crew. Tagged leaks that stopped emitting at follow-up surveys are considered repaired regardless of whether the tag was noted with 'date of repair'. If at least one tagged leak at a site is considered as "repaired", the site is considered to have undergone repairs assuming that the operator has visited the site with the intention to fix existing emissions, even if not all tagged emissions are labeled with "date of repair". Because we could not distinguish between a not repaired tagged leak from a repaired but recurred tagged leak if the leak was emitting during the follow-up survey without a "date of repair' (both are considered "not repaired"), the resulting sample size of "repaired" sites might be subset of all repaired sites.

Sites in the bi-annual and tri-annual treatment group underwent additional inspections besides the initial and final surveys. Accordingly, we define another category as "Repaired Consistently" - sites that underwent repairs consistently after each intermediate survey. 
Sites that are repaired at least once but not consistently irrespective of the survey frequency at that site, are grouped under "Repaired At Least Once". Sites that do not have any "repaired" tags throughout surveys are grouped under "Not Repaired". Based on these definitions, there are 54 sites that underwent repairs at least once, including 26 sites that are consistently repaired based on the survey frequency. Of the 26 consistently repaired sites, 15 are from the annual survey treatment group, 6 from the bi-annual survey treatment group, and 5 from the tri-annual survey treatment group. As the frequency of survey increases, the sample size of consistently repaired sites decreases. The difference between control sites and treatment sites that are not repaired is that the field crew would notify the operators of treatment sites about the emissions found on site in addition to placing physical tags on leaking components. However, operators at controls site are not notified of the results of the survey and no tags are placed on leaking components. Despite this, operators are free to conduct voluntary inspection and maintenance activities that will result in emissions reductions that are not associated with the LDAR survey.

Because the composition of site types in control and treatment groups are different, the initial numbers of average emitters in each group in Figure 5 are different (see SI section S.8). Repaired treatment sites exhibit significant reductions in the average number of leaks per site compared to control sites and non-repaired sites. Furthermore, sites that were repaired consistently saw a high reduction in the average number of leaks compared to sites that were repaired at least once. This suggest that (a) repairs are effective, (b) any observed increase in emissions likely come from new leaks and not emissions growth from existing leaks, and (c) consistent repairs of new leaks results in higher emissions reductions than inconsistent repairs. At consistently repaired treatment sites, the average number of leaks decrease by approximately $50 \%$, from 5.0 (95\% CI [3.6 - 8.0]) per site to 2.6 (95\% CI [1.8 - 4.5]) per site. At treatment sites that are repaired at least once, the average number of leaks decrease from 4.6 (95\% CI [3.2 - 8.2]) per site to 3.8 (95\% CI [2.3 - 9.7]) per site. However, at treatment sites that are not repaired, the number of leaks increased from 1.2 (95\% CI [0.8 - 1.8]) per site to $1.6(95 \%$ CI [0.2 - 2.1]) per site, indicating the impact of new leaks created between the initial and follow-up surveys. Similarly, the average number of leaks changed from $2.3(95 \%$ CI [ $1.3-3.8])$ per site to 2.0 (95\% CI [1.3 - 2.9]) per site at control sites, with the small reduction potentially associated with voluntary inspection and maintenance actions taken by the operator.

The reduction in vents between 2018 and 2019 present a more interesting challenge. Similar to leaks, the average number of vents only decreased slightly by approximately 0.3 vents per site in the control sites and 0.4 at treatment sites that were not repaired. However, by contrast, the number of vents at treatment sites that underwent leak repairs did not decrease as significantly as the number of leaks because leak emissions can be repaired by operator while vent emissions is part of operational process by design. The average number of vents reduced only slightly - from 3.5 (95\% CI [2.8 - 4.2]) per site to 3.1 (95\% CI [2.5 $-4.0])$ per site at sites that are repaired at least once and from $4.3(95 \%$ CI [3.2 - 5.4]) per site to $3.4(95 \%$ CI [2.5 - 4.9]) per site at sites that are repaired consistently. The slight reduction in the average number of vents can be attributed to several potential causes. Even though vent emissions are not the target of LDAR surveys, frequent site visits give operators more opportunity to examine emissions on site and capture anomalous venting 
events. Additionally, large vent emissions could be episodic and thus, not detected in every survey. These reasons could possibly explain the observed reduction in vent emissions, even as the number of observed vents did not decrease significantly. That the average number of vents did not decrease substantially across all sites, whether repaired or not, suggest potential influence of significant temporal variations on overall emissions estimates.

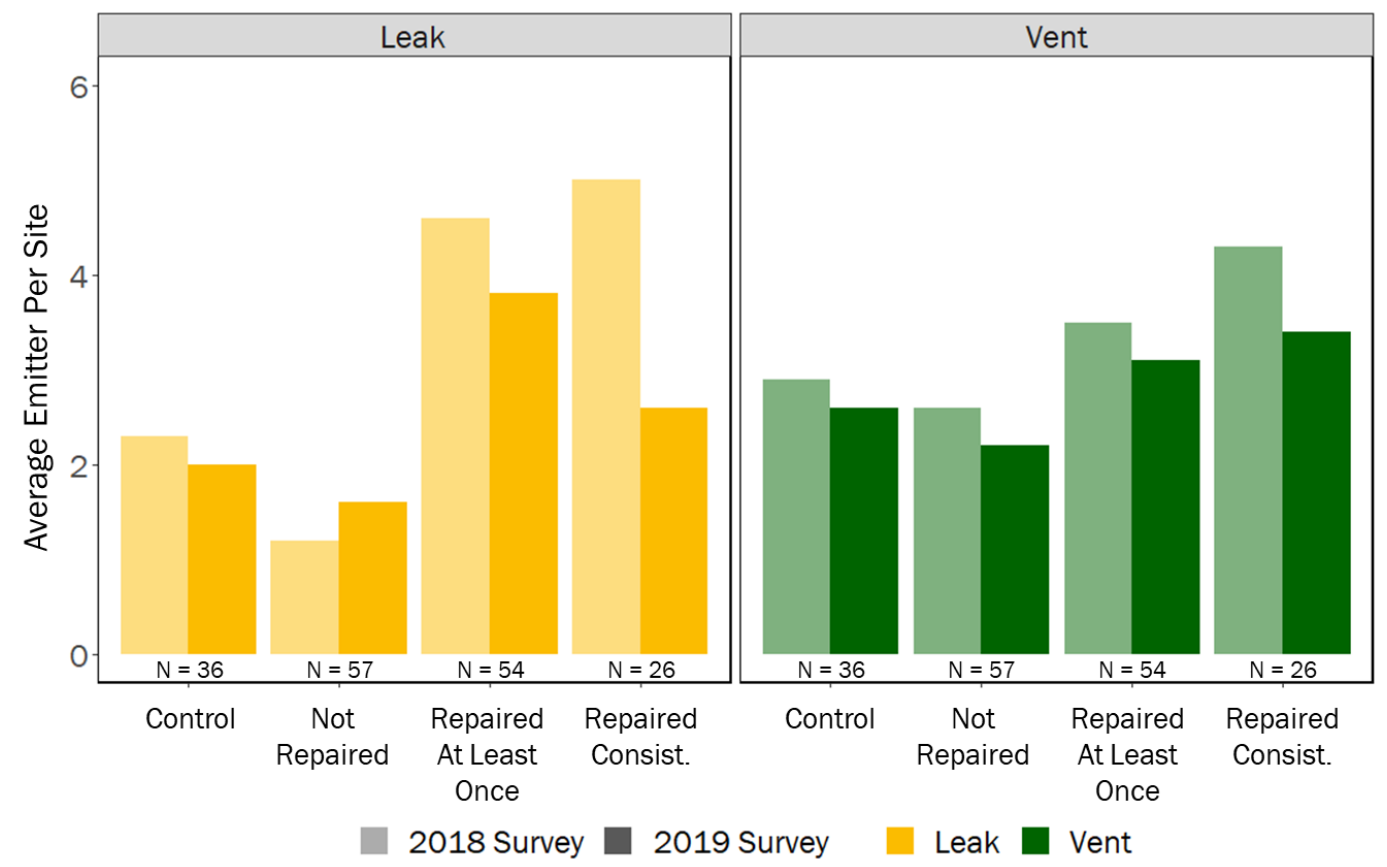

Figure 5. Site-level average count of emitters from control and treatment groups during 2018 (light colors) and 2019 (dark colors) surveys. Emitters per site are further disaggregated by leak (yellow) and vent (green) emissions. The number on top correspond to the sample size of each category. One control site was repaired by accident and removed from the analysis. As a result, there are 36 control sites. Repair activity is identified by operators' notes on physical tags. "Repaired At Least Once" include sites that are repaired at least once even if multiple leak detection surveys were conducted. "Repaired Consistently" include sites that are repaired after each leak detection survey. "Not Repaired" include sites that are not repaired at any temporal surveys.

Total emissions at control sites reduced by $36 \%$. Even though the count of leak emissions at control sites only reduces marginally, from 2.3 (95\% CI [1.3 - 3.8]) per site to 2.0 (95\% CI [1.3 - 2.9]) per site, leak emissions reduced by $57 \%$. This is understandable because operators at control sites were not made aware of the results of the LDAR survey. Because the size distribution is highly skewed, even occasional repairs of large leaks as part of routine maintenance activities (as indicated by the small reduction in the average number of leaks) can result in significant emissions reductions. For example, emissions from leaks $>100 \mathrm{~kg} \mathrm{CH}_{4} / \mathrm{d}(\mathrm{n}=5$ in 2018 and $\mathrm{n}=1$ in 2019$)$ reduced by $81 \%$ and contribute to $94 \%$ 
621 of total leak reductions at control sites. The SI discusses the impact of LDAR surveys on 622 total emissions (see SI section S.8).

\section{Discussions}

We presented results from a large-scale, component-level, controlled experiment of the effectiveness of LDAR programs in mitigating methane emissions at oil and gas facilities. Several novel features set this study apart from prior studies in the peerreviewed literature: (1) survey crews were deputized by the regulator and did not require operator outreach, which resulted in a fully randomized study and avoided the 'coalition of the willing' challenge; (2) all methane emissions, including vents, were quantified at the component-level; (3) control and treatment sites allowed analysis of LDAR program effectiveness; and (4) concurrent measurement of a large sample of gas and oil-producing sites at component-level enabled identification of site-level factors that affect emissions.

Some of the results in this study confirm prior work on methane emissions in the US and Canada. For example, we observe highly skewed emissions-size distribution - the highest emitting $5 \%$ of components contribute to $56 \%$ of total emissions and the highest $5 \%$ of emitting sites contribute to $35 \%$ of total emissions in 2019. Specifically, the 12 leaks that are larger than $100 \mathrm{~kg} \mathrm{CH}_{4} / \mathrm{d}$ are responsible for $10 \%$ of total emissions, underscoring the need for quickly finding these large emitters. Given their high emission rates and low incidence, leak detection technologies could trade off sensitivity for speed to achieve more cost-effective mitigation.

Tanks are the single largest source of emissions. Of all emitting components found on site, tank-related components contribute to $58 \%$ of total emissions despite only accounting for $16 \%$ of total emitters. That tanks emit significant volumes of methane has been observed in prior aerial-based surveys [27], [43]. Recognizing this, Colorado's department of public health and environment instituted an LDAR program specifically for tanks [34]. Such targeted policies to address known high-emitting sources could be a cost-effective way to reduce methane emissions.

Insights from this study can be used to develop targeted and cost-effective methane mitigation policies. For example, the distinction between leaks and vents often varies by jurisdiction and tends to increase uncertainty in the effectiveness of LDAR programs. As a result, categorizing emissions by leaks and vents may not be an effective distinction for emissions mitigation. Jurisdictions may want to consider the use of other metrics in developing mitigation policies, including a focus on the highest emitting equipment such as tanks. Additionally, our observations show significant variation in emissions across site types. Oil sites, due to the higher prevalence of tanks, emit more than twice that of gas sites on a per site basis. Similarly, multi-well batteries, both oil and gas, emit more than twice that of single well batteries. A differentiated policy that focuses LDAR surveys on facilities most prone to exhibit higher emissions is likely to be more costeffective than one that targets all facilities with similar LDAR stringency. Our findings align with other studies in the field on the importance of locating high-emitting sites - not 
only because of their substantial contribution to total emissions, but also because emissions reductions are driven by these large emitters. Emissions from these sites present significant mitigation opportunities and are reasonably feasible to abate given that reduction comes from routine repairing activities [17].

A key result from this study is the empirical evaluation of the effectiveness of LDAR programs. Using detailed information from physical tags attached to leaking equipment, we find there is high persistence in leaks - leaks that are repaired remain fixed in follow up surveys, while leaks that are not repaired remain emitting without significant increases in their emission rate. This implies that, (1) repairs are highly effective, and (2) any increase in measured emissions in LDAR surveys is likely to come from new leaks rather than an increase in emissions from unrepaired leaks. Given the skewed emissions distribution, the success of LDAR programs, therefore, rely on quickly finding high emitting, new leaks.

In addition to emissions, our study also consistently tracked the number of leaks and vents before and after every periodic LDAR survey - a dataset that was not available from prior research. At treatment sites that underwent repairs, LDAR surveys significantly reduce the average number of leaks per site from $5.0(95 \% \mathrm{CI}[3.6-8.0])$ to $2.6(95 \%$ CI [ $1.8-4.5])$. By contrast, control sites only exhibit a slight reduction in leaks from $2.3(95 \%$ CI $[1.3-3.8])$ to 2.0 (95\% CI [1.3 - 2.9]) per site, likely from voluntary inspection and maintenance activities. Similarly, treatment sites that are not repaired see the average number of leaks increase slightly from $1.2(95 \%$ CI $[0.8-1.8])$ to $1.6(95 \%$ CI $[0.2-2.1])$ leaks per site. This evidence, even without considering corresponding emissions reduction, clearly show the effectiveness of LDAR surveys and the importance of the repair process in addressing leaks.

Future recommendations and limitations to the data analysis in this study are presented in SI Section 9.

\section{Additional Information}

Supplementary dataset to this article is available online:

https://doi.org/10.7910/DVN/OX4QOA

\section{Acknowledgments}

We acknowledge funding from Alberta Upstream Petroleum Research Fund and Harrisburg University of Science and Technology. We thank Davis Safety Consulting Inc. for conducting the LDAR surveys in this study.

Author Contributions: APR and ARB conceived and designed the study. BB assisted with field work, study design, project management, and discussion of results. WF and CR assisted with study design, project management and provided insights on field operations and data interpretation. JW performed the analysis, generated figures, and discussed insights. All authors contributed to writing and reviewing this manuscript. 


\section{Supplementary Information}

\section{S.1 Methodology}

\section{$713 \quad$ S.1.1 Site selection}

714 All sites in the study were located within a 50 x $50 \mathrm{~km}$ area near Red Deer, Alberta. This 715 study area was chosen based on considerations of site density to minimize travel time between sites, accessibility to population centers, representativeness of oil and gas facilities to the entire production region, and logistical convenience. We randomly selected a sample of sites from the study region and verified the representativeness of production characteristics against the entire population using two-sample KolmogorovSmirnov (K-S) tests. As shown in Figure S1, we compared the cumulative distribution of gas production from gas multi-well group batteries site type in the study sample $(\mathrm{n}=117)$ with that of the population $(n=369)$. We repeated the sampling process until the null hypothesis that the two distributions did not come from the same population was rejected at the $\mathrm{p} \leq 0.05$ significance threshold. This process was performed for all site types in the study.

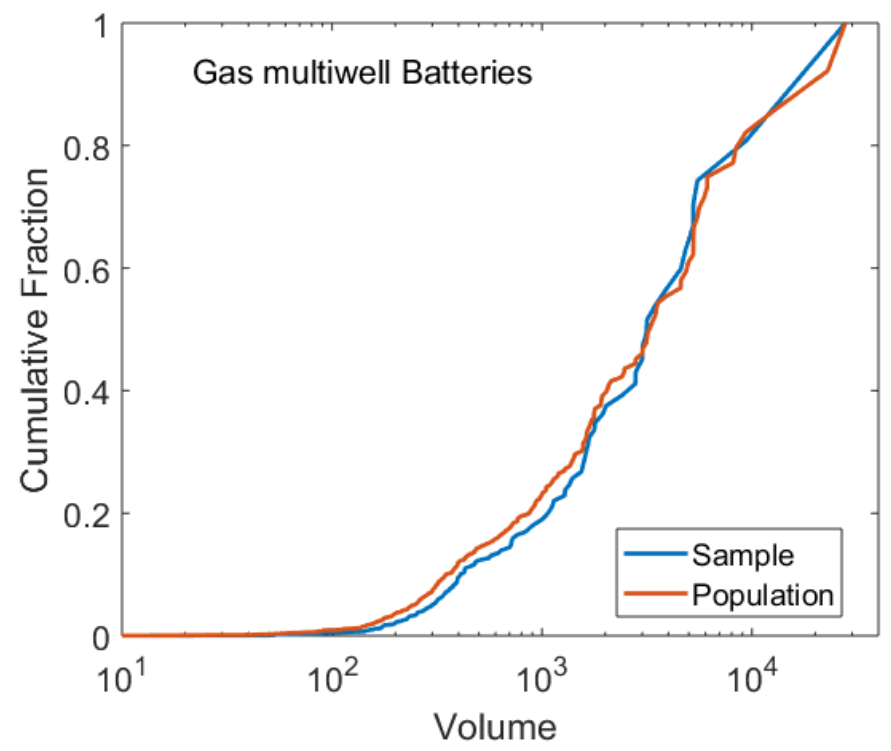

727 Figure S1: Cumulative distribution of gas production volumes at gas multiwell group 728 batteries in the study sample (blue, $n=117$ ) and the population in the Red Deer region 729 (red, $n=369$ ). We performed two sample $K-S$ test for all site types to ensure the 730 representativeness to the Red Deer production region.

\section{S.1.2 Site measurement}

732 Approximately 200 sites were selected for the study across five major site types - gas 733 single well battery (Gas SW), gas multiwell group battery (Gas MW), crude oil single734 well battery (Oil SW), crude oil multiwell group battery (Oil MW), and crude oil 735 multiwell proration battery (Oil MWPro). We conducted five component-level leak 736 detection and repair (LDAR) surveys between fall 2018 and fall 2019. However, not all 
737 sites that were selected could be measured because of shut-in wells, mismatch between 738 field observation and Petrinex database, winter conditions preventing road access, or ongoing maintenance work. In the initial 2018 survey, 17 sites were visited but not measured due to outdated information on Petrinex. 8 sites were shut in or abandoned during the time of visit and another 3 sites were inaccessible due to bad road conditions or onsite operations. Of the 194 production sites visited during the initial survey, the field crew was able to successfully measure $166(86 \%)$ of them. In the November 2018 survey, the field crew visited 45 production sites and measured 36 of them with an $80 \%$ success rate. Among the 9 sites that were not measured, 5 were shut in during the visit and another 3 were unreachable due to road conditions. 1 site was inaccessible due to an ongoing legal dispute. 44 sites were visited in the March 2019 survey, out of which 42 (95\%) sites were successfully measured. The 2 unmeasured sites were shut in the time of survey. The field crew successfully measured all 39 sites in the May 2019 survey. In the final August 2019 survey, the field crew visited 196 production sites and successfully measured $172(88 \%)$. Among the 24 unmeasured sites, 8 of them were unmeasurable due to road conditions and locked gates, 12 of them were shut in at the time of survey, 1 of them had onsite construction, and 3 of them were not measured due to outdated data on

755 Since the accessibility of a site varies over time, not all sites were successfully measured consistently in the study. For example, a tri-annual site could be unreachable in November 2018 survey due to poor road conditions. As a result, even though we were able to measure the site in the other three scheduled surveys - August 2018, May 2019, and August 2019, November 2018 data was missing. Consequently, we consider this site as "not visited on schedule" and remove it from all analysis. Table S1 summarizes the distribution of site types of successfully measured sites from each survey and Table S2 summarizes the distribution of site types of sites visited "on schedule" under each treatment group. In total, we measured 181 unique oil and gas production sites across the five surveys. In addition, we also measured emissions at 7 unique large facilities with gas gathering systems - emissions from these facilities are included in the component level analysis but excluded from the site level analysis because we are unable to separate gathering systems emissions from emissions associated with other equipment on site. After reconciling across temporal surveys, we have 148 production sites that were visited "on schedule" (excluding large facilities with gas gathering systems), including 47 sites in the annual group, 35 sites in the bi-annual group, 29 sites in the tri-annual group, and 37 sites in the control group. 


\begin{tabular}{|l|c|c|c|c|c|c|}
\hline & $\begin{array}{c}\text { Aug. } \\
\mathbf{2 0 1 8}\end{array}$ & $\begin{array}{c}\text { Nov. } \\
\mathbf{2 0 1 8}\end{array}$ & $\begin{array}{c}\text { Mar. } \\
\mathbf{2 0 1 9}\end{array}$ & $\begin{array}{c}\text { May } \\
\mathbf{2 0 1 9}\end{array}$ & $\begin{array}{c}\text { Aug. } \\
\mathbf{2 0 1 9}\end{array}$ & $\begin{array}{c}\text { Total } \\
\text { Unique }\end{array}$ \\
\hline $\begin{array}{l}\text { Site } \\
\text { Visited }\end{array}$ & 166 & 36 & 42 & 39 & 172 & 181 \\
\hline Gas MW & 20 & 5 & 5 & 5 & 21 & 22 \\
\hline Gas SW & 58 & 11 & 15 & 13 & 56 & 61 \\
\hline Oil MW & 9 & 2 & 4 & 2 & 11 & 11 \\
\hline $\begin{array}{l}\text { Oil } \\
\text { MWPro }\end{array}$ & 18 & 5 & 4 & 5 & 17 & 18 \\
\hline Oil SW & 61 & 13 & 14 & 14 & 67 & 69 \\
\hline
\end{tabular}

Table S2: Distribution of sites visited "on schedule” in each group.

\begin{tabular}{|l|c|c|c|c|c|}
\hline & Annual & Bi-Annual & Tri-Annual & Control & Total \\
\hline Site Visited & 47 & 35 & 29 & 37 & 148 \\
\hline Gas MW & 7 & 5 & 5 & 2 & 19 \\
\hline Gas SW & 15 & 11 & 8 & 14 & 48 \\
\hline Oil MW & 3 & 2 & 0 & 3 & 8 \\
\hline Oil MWPro & 5 & 4 & 4 & 4 & 17 \\
\hline Oil SW & 17 & 13 & 12 & 14 & 56 \\
\hline
\end{tabular}

\section{S.1.3 Unit conversions}

All emission flow rates measurement in this study are reported in mass flow rates.

779 Measurement volumes are converted to $\mathrm{kg} / \mathrm{d}$ based on Equation (S1).

780 mass flow rate $\left[\frac{\mathrm{kg}}{\mathrm{d}}\right]=\frac{\text { molar fraction of } \mathrm{CH}_{4} * \text { molar weight } * \text { volume flow rate } * 24}{\text { molar volume } * \text { liter to } \mathrm{scf} \text { conversion factor } * 1000}$

- Methane mole fraction in resource $=0.82$ [12]

- $\quad$ molar weight $=16.04 \mathrm{~g} \mathrm{~mol}^{-1}$

- molar volume at STP = $23.645 \mathrm{~L} \mathrm{~mol}^{-1}$

- liter to standard cubic feet conversion factor $=0.0353147$

788

Proportional loss rates (PLR) are calculated both on a natural gas production basis as is standard in the methane emissions literature, as well as an energy basis to account for both oil and gas production [9], [14], [21], [22], [29], [46], [47]. Monthly average gas and oil production volumes are taken from Petrinex database and converted to energy basis 
using equations S2 and S3 [48].

$$
\begin{gathered}
\text { gas production energy }(G J)=\text { gas production volume }\left(10^{3} \mathrm{~m}^{3}\right) * 38.3(G J) \\
\text { oil production energy }(G J)=\text { oil produciton volume }\left(\mathrm{m}^{3}\right) * 39(\mathrm{GJ})
\end{gathered}
$$

The gas-production based proportional loss rate $\left(\mathrm{PLR}_{\mathrm{g}}\right)$ and energy-based proportional loss rate $\left(\mathrm{PLR}_{\mathrm{e}}\right)$ are calculated using equations S4 and S5.

$$
\begin{gathered}
P L R_{g}=\text { methane emitted } / \text { methane produced } \\
P L R_{e}=\text { energy emitted } / \text { energy produced }
\end{gathered}
$$

\section{S.1.4 Missing data methodology}

95\% (2768 out of 2910) of all emitting components are quantified directly with QOGI technology across surveys. There are two reasons for not being able to quantify an emitter: 1) the emission is too small to measure; 2) site complications prevent the field crew from quantifying the emission, including but not limited to reflection from the sun and interference from other emitters nearby. Table S3 shows the detailed breakdown of emitters that are too small to measure (TSTM) or could not quantify (CNQ) due to site complications. The November 2018 survey has the highest rate of CNQ, which is mainly due to reflection from snow and interference from nearby heaters.

Table S3: Emitter quantification breakdown (including large facilities with gas gathering systems)

\begin{tabular}{|l|c|c|c|c|c|c|c|}
\hline & $\begin{array}{c}\text { Total } \\
\text { Emitters }\end{array}$ & TSTM & $\begin{array}{c}\text { \% total } \\
\text { emitter }\end{array}$ & CNQ & $\begin{array}{c}\text { \% total } \\
\text { emitter }\end{array}$ & $\begin{array}{c}\text { Direct } \\
\text { Quant. }\end{array}$ & $\begin{array}{c}\% \text { total } \\
\text { emitters }\end{array}$ \\
\hline $\begin{array}{l}\text { August } \\
\mathbf{2 0 1 8}\end{array}$ & 1025 & 16 & $1.2 \%$ & 66 & $6.4 \%$ & 943 & $92.0 \%$ \\
\hline $\begin{array}{l}\text { November } \\
\mathbf{2 0 1 8}\end{array}$ & 212 & 0 & $0.0 \%$ & 38 & $17.9 \%$ & 174 & $82.1 \%$ \\
\hline $\begin{array}{l}\text { March } \\
\mathbf{2 0 1 9}\end{array}$ & 275 & 0 & $0.0 \%$ & 3 & $1.1 \%$ & 272 & $98.9 \%$ \\
\hline $\begin{array}{l}\text { May } \\
\mathbf{2 0 1 9}\end{array}$ & 394 & 2 & $0.5 \%$ & 15 & $3.8 \%$ & 377 & $95.6 \%$ \\
\hline $\begin{array}{l}\text { August } \\
\mathbf{2 0 1 9}\end{array}$ & 1004 & 0 & $0.0 \%$ & 2 & $0.2 \%$ & 1002 & $99.8 \%$ \\
\hline
\end{tabular}

*Percentage may not total to $100 \%$ due to rounding.

To address TSTM emitters, we assign an emission rate corresponding to the smallest quantified emission rate across the major component types. To address CNQ emitters, we assign the average emission rate of the corresponding component type from each survey. To evaluate the impact of our methodology, we conducted statistical tests to compare the mean and 95\% confidence interval of 1 ) the dataset without CNQ and TSTM emitters and 2) the dataset with processed CNQ and TSTM emitters. As Table S4 shows, the mean emission differences between the two datasets are $<0.5 \mathrm{~kg} \mathrm{CH}_{4} / \mathrm{d}$ and the $95 \%$ confidence intervals overlap almost completely, indicating minimal difference introduced between 
the two datasets. Welch two sample t-test was also conducted to investigate whether the difference is statistically significant. The resulting $p$-values are all $>0.95$, much higher than the 0.05 threshold to reject the null hypothesis - the true difference in means is zero. In other words, our missing data methodology did not introduce statistically significant differences to the dataset.

Table S4: Impact of missing data methodology (including large facilities with gas gathering systems, emissions unit in $\mathrm{kg} / \mathrm{d}$ )

\begin{tabular}{|c|c|c|c|c|c|c|}
\hline & \multirow{2}{*}{$\begin{array}{c}\text { Total } \\
\text { Emitters }\end{array}$} & \multicolumn{2}{|c|}{$\begin{array}{c}\text { Without CNQ \& } \\
\text { TSTM } \\
\end{array}$} & \multicolumn{2}{|c|}{ With CNQ \& TSTM } & \multirow{2}{*}{$\begin{array}{c}\text { T-test } \\
p \text {-value } \\
\end{array}$} \\
\hline & & Mean & $95 \% C I$ & Mean & $95 \% C I$ & \\
\hline $\begin{array}{c}\text { August } \\
2018\end{array}$ & 1025 & 49.8 & $39.4-61.7$ & 49.4 & $39.7-60.4$ & 0.96 \\
\hline $\begin{array}{c}\text { November } \\
2018\end{array}$ & 212 & 11.5 & $8.4-15.3$ & 11.3 & $8.7-14.4$ & 0.95 \\
\hline $\begin{array}{l}\text { March } \\
2019\end{array}$ & 275 & 29.1 & $19.7-40.8$ & 29.1 & $19.9-40.7$ & 0.995 \\
\hline $\begin{array}{l}\text { May } \\
2019\end{array}$ & 394 & 23.5 & $15.1-34.7$ & 23.8 & $15.7-34.2$ & 0.96 \\
\hline $\begin{array}{c}\text { August } \\
2019\end{array}$ & 1004 & 28.7 & $23.1-35.6$ & 28.6 & $23.0-35.8$ & 0.99 \\
\hline
\end{tabular}

*Percentage may not total to $100 \%$ due to rounding.

\section{S.2 Component-level emissions}

\section{S.2.1 Leaker emissions factors}

The main text presented results and analysis from the initial survey (August 2018) and the final survey (August 2019). In this section, we present statistical results on component-level emissions from all surveys. For all survey statistics, 95\% confidence intervals are calculated based on bootstrapping with 10,000 samples with replacement.

\section{S.2.1.1 August 2018 survey ('initial survey')}

All sites in the study were measured as part of the initial survey in August 2018. The average emission rate of all emitters is $49 \mathrm{~kg} \mathrm{CH}_{4} / \mathrm{d}$ [41 - 62]. The top 5\% of emitters contribute to $62 \%$ of total emissions. Leaks contribute to $31 \%$ of total emissions and vents contribute to $69 \%$ of total emissions. Table S5 shows the summary statistics for component-level emissions across all sites. These results correspond to the data show in Figure 2 in the main text. Tank related emissions contribute to $52 \%$ of total emissions despite only comprising $18 \%$ of total emitters.

\section{Table S5: Summary statistics for fall 2018 survey (including large facilities with gas} gathering systems) 


\begin{tabular}{|l|c|c|c|}
\hline Component & $\begin{array}{c}\text { Leaker Emission } \\
\text { Factor }(\mathbf{k g} / \mathbf{d})\end{array}$ & $\begin{array}{c}\text { \% Total } \\
\text { Emission* }\end{array}$ & $\begin{array}{c}\text { \% Total } \\
\text { Emitter* }\end{array}$ \\
\hline Flange/Connector & $23[11-66]$ & $8 \%$ & $17 \%$ \\
\hline Open-Ended Line (Non-Tank) & $32[25-47]$ & $17 \%$ & $26 \%$ \\
\hline Open-Ended Line (Tank) & $160[112-241]$ & $39 \%$ & $12 \%$ \\
\hline Others & $21[12-37]$ & $1 \%$ & $3 \%$ \\
\hline Pneumatics & $44[29-73]$ & $19 \%$ & $22 \%$ \\
\hline Tank Level Indicator & $99[62-153]$ & $3 \%$ & $2 \%$ \\
\hline Thief Hatch & $183[97-341]$ & $9 \%$ & $3 \%$ \\
\hline Valves & $10[7-17]$ & $3 \%$ & $16 \%$ \\
\hline Not Tank Related & $29[23-39]$ & $48 \%$ & $82 \%$ \\
\hline Tank Related & $142[107-200]$ & $52 \%$ & $18 \%$ \\
\hline All Emitters & $49[41-62]$ & - & - \\
\hline
\end{tabular}

*Percentage may not total to $100 \%$ due to rounding.

$841 \quad$ S.2.1.2 November 2018 survey

842 In November 2018, we conducted the first follow up survey of the tri-annual treatment 843 group. Table S6 shows the summary statistics for component-level emissions. A total of 844146 emitters are found across 29 sites that are visited on schedule, averaging 5 emitters 845 per site (excluding large facilities with gas gathering systems). The average emission rate 846 of all emitters is $13 \mathrm{~kg} \mathrm{CH}_{4} / \mathrm{d}$ [9 - 17]. Leaks contribute to $30 \%$ of total emissions with an average emission rate of $8 \mathrm{~kg} \mathrm{CH}_{4} / \mathrm{d}[5-11]$. Vents contribute to $70 \%$ of total emissions with an average emission rate of $16 \mathrm{~kg} \mathrm{CH}_{4} / \mathrm{d}[11-23] .50 \%$ of the total emissions come from emitters emitting at least $38 \mathrm{~kg} \mathrm{CH}_{4} / \mathrm{d}$. The top $5 \%$ of emitters contribute to $31 \%$ of total emissions. Tank related emitters such as tank-related open-ended lines and thief hatch have the highest average emission rate of $43 \mathrm{~kg} \mathrm{CH}_{4} / \mathrm{d}[20-76]$ and $33 \mathrm{~kg} \mathrm{CH} / \mathrm{d}$ [4-48], respectively. Together they contribute to $35 \%$ of total emissions from $11 \%$ of emitters. By contrast, components such as non-tank related open-ended lines and valves constitute $42 \%$ of total emitters and yet only contribute to $25 \%$ of total emissions.

857 Table S6: Summary statistics for the November 2018 survey

\begin{tabular}{|l|c|c|c|c|}
\hline Component & $\begin{array}{c}\text { Emitter/ } \\
\text { Site }\end{array}$ & $\begin{array}{c}\text { Leaker Emission } \\
\text { Factor (kg/d) }\end{array}$ & $\begin{array}{c}\text { \% Total } \\
\text { Emission* }\end{array}$ & $\begin{array}{c}\% \text { Total } \\
\text { Emitter* }\end{array}$ \\
\hline Flange/Connector & 0.3 & $6.1[2.1-12.8]$ & $3 \%$ & $6 \%$ \\
\hline $\begin{array}{l}\text { Open-Ended Line (Non- } \\
\text { Tank) }\end{array}$ & 1.3 & $8.9[6.0-11.9]$ & $18 \%$ & $26 \%$ \\
\hline Open-Ended Line (Tank) & 0.4 & $43.1[20.1-76.0]$ & $30 \%$ & $9 \%$ \\
\hline
\end{tabular}




\begin{tabular}{|l|c|c|c|c|}
\hline Others & 0.03 & $19.0\left[\mathrm{NA}^{* *}\right]$ & $1 \%$ & $1 \%$ \\
\hline Pneumatics & 2.0 & $10.9[7.3-15.3]$ & $35 \%$ & $40 \%$ \\
\hline Thief Hatch & 0.1 & $32.9[4.1-48.0]$ & $5 \%$ & $2 \%$ \\
\hline Valves & 0.8 & $5.5[2.3-10.5]$ & $7 \%$ & $16 \%$ \\
\hline
\end{tabular}

*Percentage may not total to $100 \%$ due to rounding.

**There is only one "Others" emitter in the November 2018 survey.

\section{S.2.1.3 March 2019 survey}

In March 2019, we conducted the first follow up survey of the bi-annual treatment group. Table S7 shows the summary statistics for component-level emissions. A total of 262 emitters are found across 35 sites that are visited on schedule, averaging 7.5 emitters per site (excluding large facilities with gas gathering systems). The average emission rate of all emitters is $30 \mathrm{~kg} \mathrm{CH}_{4} / \mathrm{d}$ [20 - 42]. Leak emissions constitute $15 \%$ of total emissions with an average of $10 \mathrm{~kg} \mathrm{CH}_{4} / \mathrm{d}[7$ - 14]. Vent emissions makes up $85 \%$ of total emissions with an average of $45 \mathrm{~kg} \mathrm{CH}_{4} / \mathrm{d}$ [29 - 66]. $50 \%$ of the total emissions come from emitters emitting at least $175 \mathrm{~kg} \mathrm{CH}_{4} / \mathrm{d}$. The top $5 \%$ of emitters contribute to $56 \%$ of total emissions. Tank related open-ended line is the most significant emitter, contributing to $40 \%$ of total emissions while only constitute $16 \%$ of total emitters. Pneumatics is the most common emitting component, averaging 2.9 emitters per site but only contributes to $12 \%$ of total emissions.

Table S7: Summary statistics for the March 2019 survey

\begin{tabular}{|l|c|c|c|c|}
\hline Component & $\begin{array}{c}\text { Emitter/ } \\
\text { Site }\end{array}$ & $\begin{array}{c}\text { Leaker Emission } \\
\text { Factor (kg/d) }\end{array}$ & $\begin{array}{c}\text { \% Total } \\
\text { Emission* }\end{array}$ & $\begin{array}{c}\text { \% Total } \\
\text { Emitter* }\end{array}$ \\
\hline Flange/Connector & 1.7 & $13.5[5.0-27.3]$ & $9 \%$ & $19 \%$ \\
\hline Open-Ended Line (Non-Tank) & 2.1 & $42.9[19.9-80.1]$ & $34 \%$ & $23 \%$ \\
\hline Open-Ended Line (Tank) & 1.4 & $74.1[36.7-120.1]$ & $40 \%$ & $16 \%$ \\
\hline Others & 0.1 & $6.2[4.3-8.2]$ & $0 \%$ & $1 \%$ \\
\hline Pneumatics & 2.9 & $11.3[7.9-15.5]$ & $12 \%$ & $32 \%$ \\
\hline Tank Level Indicator & 0.1 & $77.3[8.2-146.4]$ & $2 \%$ & $1 \%$ \\
\hline Thief Hatch & 0.1 & $8.2[2.9-13.4]$ & $0 \%$ & $1 \%$ \\
\hline Valves & 0.7 & $10.6[2.9-22.7]$ & $3 \%$ & $7 \%$ \\
\hline
\end{tabular}

*Percentage may not total to $100 \%$ due to rounding.

\section{S.2.1.4 May 2019 survey}

In May 2019, we conducted the second follow up survey of the tri-annual treatment group. Table S8 shows the summary statistics for component-level emissions. A total of 258 emitters are found across 29 sites that are visited on schedule, averaging 8.9 emitters 
per site (excluding large facilities with gas gathering systems). The average emission rate of all emitters on these sites is $32 \mathrm{~kg} \mathrm{CH}_{4} / \mathrm{d}$ [20 - 48]. Leak emissions contribute to $34 \%$ of total emissions with an average of $19 \mathrm{~kg} \mathrm{CH}_{4} / \mathrm{d}$ [6 - 42]. Vent emissions constitute the rest $66 \%$ of total emissions with an average of $50 \mathrm{~kg} \mathrm{CH}_{4} / \mathrm{d}[32-70] .50 \%$ of emissions come from emitters emitting at least $355 \mathrm{~kg} \mathrm{CH}_{4} / \mathrm{d}$. The top $5 \%$ of emitters contribute to $65 \%$ of total emissions. Tank related open-ended line is the single largest source of emissions, contributing to $52 \%$ of total emissions with an average of $98 \mathrm{~kg} \mathrm{CH}_{4} / \mathrm{d}$ [58 142] while only constituting $17 \%$ of total emitters. Tank level indicator and thief hatch also have high averages of $105 \mathrm{~kg} \mathrm{CH}_{4} / \mathrm{d}$ [5 - 299] and $99 \mathrm{~kg} \mathrm{CH}_{4} / \mathrm{d}$ [49 - 149], respectively. The most common emitters are pneumatics and valves, each making up of $29 \%$ and $25 \%$ of total emitters. However, their total contribution to emissions is only $35 \%$.

Table S8: Summary statistics for the May 2019 survey

\begin{tabular}{|l|c|c|c|c|}
\hline Component & $\begin{array}{c}\text { Emitter/ } \\
\text { Site }\end{array}$ & $\begin{array}{c}\text { Leaker Emission } \\
\text { Factor (kg/d) }\end{array}$ & $\begin{array}{c}\text { \% Total } \\
\text { Emission* }\end{array}$ & $\begin{array}{c}\text { \% Total } \\
\text { Emitter* }\end{array}$ \\
\hline Flange/Connector & 1.7 & $6.5[4.0-9.5]$ & $4 \%$ & $19 \%$ \\
\hline Open-Ended Line (Non-Tank) & 0.5 & $14.2[5.4-28.2]$ & $3 \%$ & $6 \%$ \\
\hline Open-Ended Line (Tank) & 1.5 & $98.4[58.2-142.3]$ & $52 \%$ & $17 \%$ \\
\hline Others & 0.1 & $2.3[1.7-3.1]$ & $0 \%$ & $2 \%$ \\
\hline Pneumatics & 2.6 & $28.5[7.3-69.0]$ & $26 \%$ & $29 \%$ \\
\hline Tank Level Indicator & 0.1 & $104.8[4.9-298.7]$ & $4 \%$ & $1 \%$ \\
\hline Thief Hatch & 0.1 & $98.9[49.1-148.6]$ & $2 \%$ & $1 \%$ \\
\hline Valves & 2.2 & $11.8[3.4-23.2]$ & $9 \%$ & $25 \%$ \\
\hline
\end{tabular}

*Percentage may not total to $100 \%$ due to rounding.

\section{S.2.1.5 August 2019 survey ('final survey')}

All sites in the study were measured in the final August 2019 survey. Table S9 shows the summary statistics for component-level emissions. The average emission rate of all emitters is $29 \mathrm{~kg} \mathrm{CH}_{4} / \mathrm{d}$ [24 - 38]. The top 5\% of emitters contribute to $56 \%$ of total emissions. Leaks contribute to $24 \%$ of total emissions and vents contribute to $76 \%$ of total emissions. Tank related emissions contribute to $58 \%$ of total emissions despite only comprising $16 \%$ of total emitters.

Table S9: Summary statistics for fall 2019 survey (including large facilities with gas gathering systems) 


\begin{tabular}{|l|c|c|c|}
\hline Component & $\begin{array}{c}\text { Leaker Emission } \\
\text { Factor (kg/d) }\end{array}$ & $\begin{array}{c}\text { \% Total } \\
\text { Emission* }\end{array}$ & $\begin{array}{c}\text { \% Total } \\
\text { Emitter* }\end{array}$ \\
\hline Flange/Connector & $12[7-22]$ & $10 \%$ & $24 \%$ \\
\hline Open-Ended Line (Non-Tank) & $53[36-78]$ & $19 \%$ & $10 \%$ \\
\hline Open-Ended Line (Tank) & $104[77-185]$ & $43 \%$ & $12 \%$ \\
\hline Others & $7[4-10]$ & $0 \%$ & $0 \%$ \\
\hline Pneumatics & $12[11-15]$ & $14 \%$ & $33 \%$ \\
\hline Tank Level Indicator & $16[6-34]$ & $0 \%$ & $0 \%$ \\
\hline Thief Hatch & $80[45-138]$ & $4 \%$ & $2 \%$ \\
\hline Valves & $14[8-27]$ & $9 \%$ & $18 \%$ \\
\hline Not Tank Related & $14[12-18]$ & $42 \%$ & $84 \%$ \\
\hline Tank Related & $105[81-165]$ & $58 \%$ & $16 \%$ \\
\hline All Emitters & $29[24-38]$ & - & - \\
\hline
\end{tabular}

*Percentage may not total to $100 \%$ due to rounding.

$903 \quad$ S.2.2 Emissions size distribution between initial and final surveys

904 Figure S2 compares size distribution of component-level leaks, vents, and total emissions 905 in the initial (fall 2018) and final (fall 2019) surveys. In fall 2018 survey (Figure S2 (a)), $90650 \%$ of total emissions come from emitters emitting at least $454 \mathrm{~kg} \mathrm{CH}_{4} / \mathrm{d}$. When 907 disaggregated by leak and vent emissions, 50\% of leak emissions come from emitters 908 emitting at least $643 \mathrm{~kg} \mathrm{CH}_{4} / \mathrm{d}$, whereas $50 \%$ of vent emissions come from emitters 909 emitting at least $284 \mathrm{~kg} \mathrm{CH}_{4} / \mathrm{d}$. There are 7 leaks that are emitting $>643 \mathrm{~kg} \mathrm{CH} / \mathrm{d}$ with 910 an average of $1060 \mathrm{~kg} \mathrm{CH}_{4} / \mathrm{d}$. These 7 leaks only make up of $1 \%$ of total leak emitters, 911 demonstrating the significant impact of large leaks on overall leak emissions. On the 912 other hand, there are 22 vents emitting at least $284 \mathrm{~kg} \mathrm{CH}_{4} / \mathrm{d}$ with an average of $797 \mathrm{~kg}$ $913 \mathrm{CH}_{4} / \mathrm{d}$. These 22 vents constitute $5 \%$ of total vent emitters. In fall 2019 survey (Figure S2 914 (b)), $50 \%$ of all emissions come from emitters $>200 \mathrm{~kg} \mathrm{CH}_{4} / \mathrm{d}$. When disaggregated by 915 leak and vent emissions, 50\% of leak emissions come from emitters emitting at least 64 $916 \mathrm{~kg} \mathrm{CH}_{4} / \mathrm{d}$, whereas $50 \%$ of vent emissions come from emitters emitting at least $223 \mathrm{~kg}$ $917 \mathrm{CH}_{4} / \mathrm{d}$. Leak emissions reduced significantly in 2019 - the largest leak emitter in 2019 is 918 emitting at $567 \mathrm{~kg} \mathrm{CH}_{4} / \mathrm{d}$, even smaller than the $643 \mathrm{~kg} \mathrm{CH}_{4} / \mathrm{d}$ cutoff rate in 2018. 

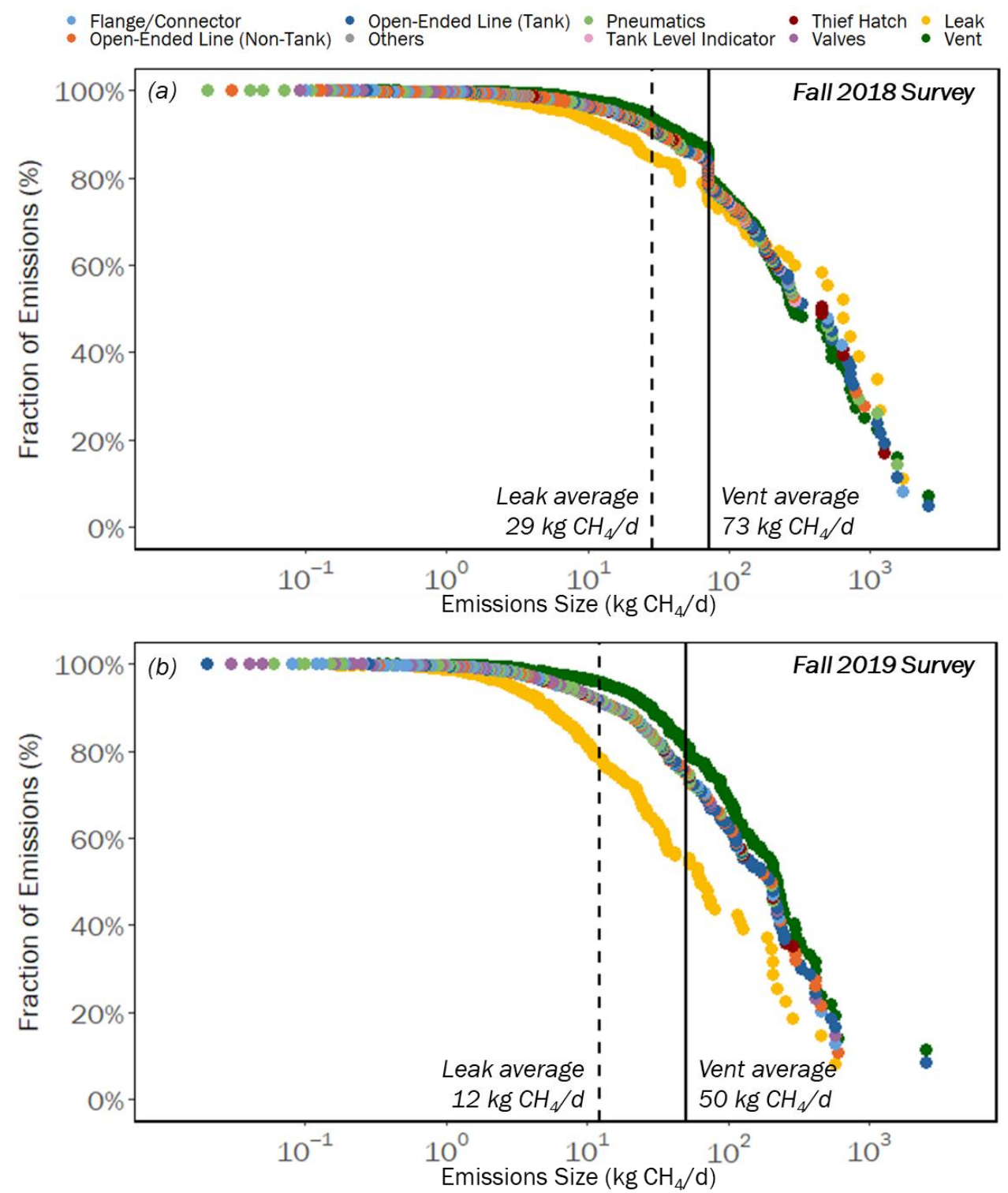

920 Figure S2: Component-level emission rate distribution in (a) Fall 2018 and (b) Fall 2019 921 surveys. Both graphs show the cumulative distribution of leak (yellow), vent (green), and 922 total (multi-color) emissions as a function of rank-ordered emission sizes disaggregated 923 by six major component types. The dashed vertical lines indicate average leak emissions, 924 and the solid vertical lines indicate average vent emissions.

\section{S.3 Component-level repair analysis}

926 Following the tagging logic established in Section 3.4 of the main text, we further 927 investigate the distribution of tagged component-level leak emissions. Table S10 shows 928 the mean and confidence interval of the emission rate of tagged emissions (Figure 4, 929 main text).

930 Table S10: Average emission rate summary statistics of tagged leak emissions (unit in 


\begin{tabular}{|l|c|c|c|}
\hline All Component & Flange/Connector & Pneumatics & Valves \\
\hline Initial Survey & $3.6[3.0-4.6]$ & $38.6[16.4-92.6]$ & $3.6[2.9-4.8]$ \\
\hline Follow-up Survey & $3.1[2.5-4.1]$ & $16.6[3.5-79.8]$ & $3.0[2.3-4.1]$ \\
\hline Not Repaired & Flange/Connector & Pneumatics & Valves \\
\hline Initial Survey & $4.0[3.3-5.3]$ & $21.3[6.9-87.6]$ & $3.3[2.5-4.8]$ \\
\hline Follow-up Survey & $4.2[3.4-5.4]$ & $32.1[6.7-132.6]$ & $4.2[3.3-5.7]$ \\
\hline Repaired & Flange/Connector & Pneumatics & Valves \\
\hline Initial Survey & $2.5[1.7-4.7]$ & $56.9[12.1-179.8]$ & $4.4[3.0-6.7]$ \\
\hline Follow-up Survey & $0.4[0.0-1.1]$ & $0.2[0.0-0.9]$ & $0.04[0.0-0.1]$ \\
\hline
\end{tabular}

\section{S.4 Effect of time between surveys}

We disaggregate sites in the treatment group based on the time between two consecutive surveys - sites that have been re-visited within $1-4$ months, $5-8$ months, and $9-13$ months. Table S11 shows the treatment sites that are included in each group. The $1-4$ months group includes sites from the tri-annual treatment group and the $9-13$ months group includes sites from the annual treatment group. However, the $5-8$ months group contains sites from both the bi-annual treatment group and the tri-annual treatment group. As a result, we separate the $5-8$ months into bi-annual and tri-annual groups when comparing emissions changes in Figure S3.

942 Table S11: Categorization of sites by time between initial and follow-up surveys

\begin{tabular}{|l|c|c|c|c|}
\hline $\begin{array}{l}\text { Time between } \\
\text { Consecutive } \\
\text { Surveys (Months) }\end{array}$ & $\begin{array}{c}\text { Treatment } \\
\text { Group }\end{array}$ & First Survey & $\begin{array}{c}\text { Follow Up } \\
\text { Survey }\end{array}$ & Count \\
\hline $1-4$ & Tri-Annual & August 2018 & November 2018 & 29 \\
\hline $1-4$ & Tri-Annual & May 2019 & August 2019 & 29 \\
\hline $5-8$ & Bi-Annual & August 2018 & March 2019 & 35 \\
\hline $5-8$ & Bi-Annual & March 2019 & August 2019 & 35 \\
\hline $5-8$ & Tri-Annual & November 2018 & May 2019 & 29 \\
\hline $9-13$ & Annual & August 2018 & August 2019 & 47 \\
\hline
\end{tabular}


Figure S3 shows average site-level emissions in the initial and follow-up surveys as a function of the time between surveys. Emissions at sites that are revisited after $1-4$ months reduced by a statistically significant $67 \%$ on average. Emissions at bi-annual sites that are revisited after $5-8$ months reduced by $34 \%$ on average, similar to the $36 \%$ reduction from sites that are revisited after $9-13$ months. Nevertheless, emissions at triannual sites that are revisited $5-8$ months increased by more than three-fold. The increase is largely attributable to the low emissions observed in the November 2018 survey mainly from the repairs undertaken by operators between the first August 2018 survey and the November 2018 survey. As a result, the follow up survey in May 2019 is compared to a much lower initial emissions in November 2018. This analysis includes all 955

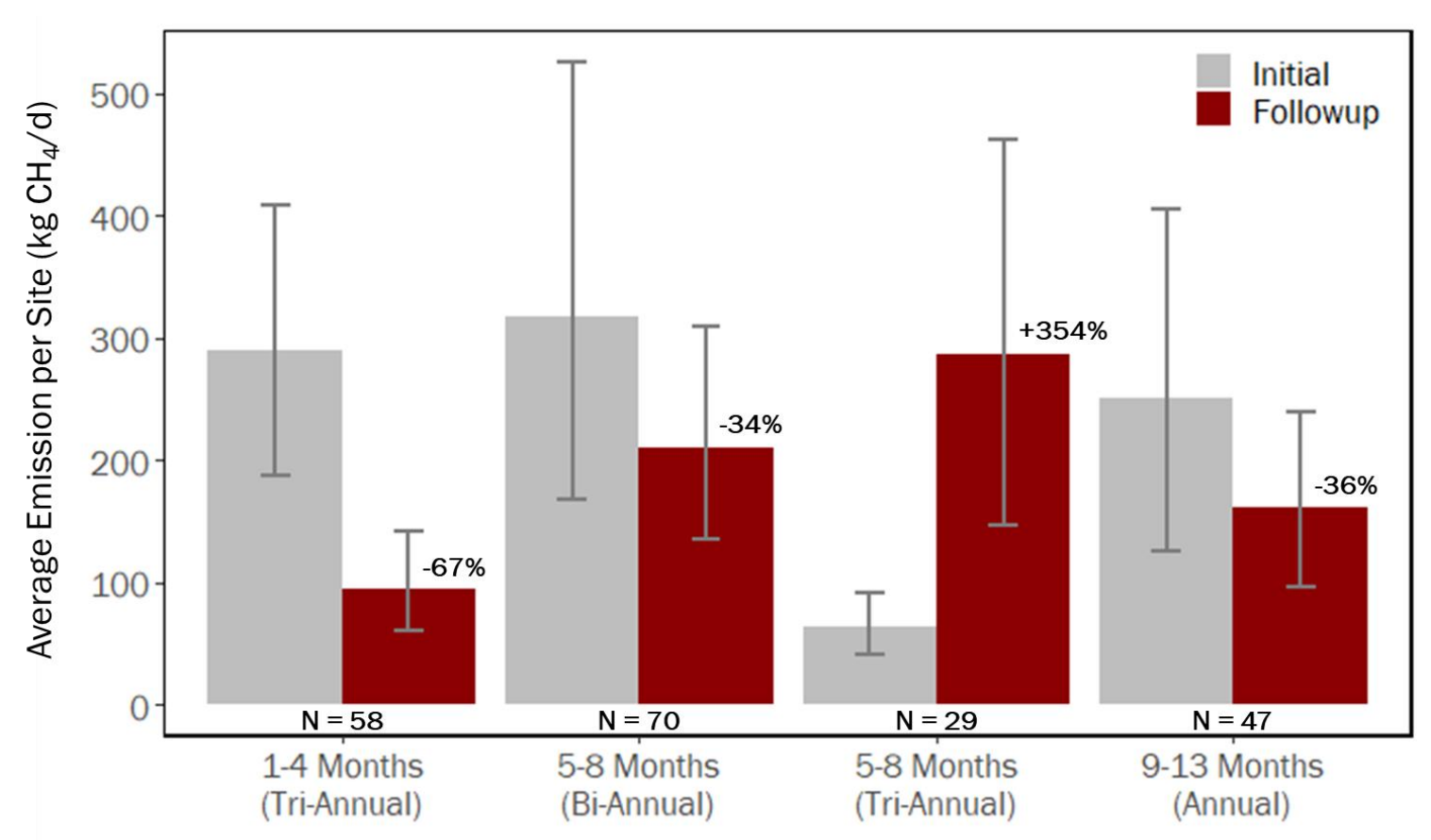
sites within each survey group, irrespective of whether the site was repaired.

Figure S3: Comparison of emission changes disaggregated by time between surveys. The gray bars represent average site level emissions from the initial survey, as listed in Table S11. The red bars represent average site level emissions from the follow up survey. The percentage above the red bars indicate the percentage change of average site level emissions since the initial survey. The numbers below bars indicate the number of sites within each group. Error bars represent 95\% confidence interval with 10000 bootstrapped samples with replacement. Large facilities with gathering systems are not included in this graph.

\section{S.5 Comparison with other methane emissions studies}

We compare methane emissions measured in this work with that of other studies in Canada and the US in regions with similar geological and production characteristics. To make direct comparisons with other studies possible, we first estimate proportional loss 
rates to normalize emissions estimates and account for changes in production volumes

969 over time. In this analysis, we include measurements reported in the following studies:

970 Red Deer region in Alberta (Zavala-Araiza et al. [13], Western Canada (Chan et al. [11]),

971 Permian basin in Texas (Zhang et al. [46]), and Bakken shale in North Dakota (Peischl et

972 al. [49]).

Figure S4 shows gas production-based $\left(\mathrm{PLR}_{\mathrm{g}}\right)$ and energy-based $\left(\mathrm{PLR}_{\mathrm{e}}\right)$ proportional loss rates from the final survey in 2019 disaggregated by site types. There are 12 sites for which we could not find production information on Petrinex- they are removed from this calculation. Furthermore, there were 5 sites that reported neither gas nor oil production but still had measurable emissions and are excluded from this figure. The overall gas production-based proportional loss rate across all sites is 3.3\% (Figure S4(a)), which is comparable to other studies in the region. For example, Zavala-Araiza et al. estimate the PLR $_{\mathrm{g}}$ to be $3 \%$ in 2018 using mobile, ground-based tracer release methods [13].

Furthermore, they verified this ground data with aerial measurements, reporting similar methane emissions. In a more recent study from Environment and Climate Change Canada, Chan et al. estimated methane emissions from Alberta and Saskatchewan using fixed tower sites and report an average gas-based methane loss rate of about $4.2 \%$ [11]. In the US, recent satellite-based observations of methane emission in the Permian basin a similar region to Alberta with both oil and unconventional gas production - exhibit a gas-based methane loss rate of 3.7\% [46]. In the Bakken region in North Dakota with mainly tight-oil production, aerial surveys report an estimate methane loss rate of $6.3 \%$ [49].

In our study, the PLRg of oil sites is $4.5 \%$, more than twice that of gas sites at $1.9 \%$. The high PLR $_{\mathrm{g}}$ at oil sites can be attributed to the combination of higher methane emissions associated with higher incidence of tanks and lower gas production at oil sites (see main text Figure 3). The PLRg of multi-well batteries is half that of single well batteries, each emitting $2.4 \%$ and $4.8 \%$ of their gas production respectively. As shown in Figure 3 in the main text, multi-well batteries' average emission is 2.2 times that of single well batteries. However, multi-well batteries have much higher gas productions - the average gas production volume of multi-well batteries is 4.1 times that of single well batteries, resulting in lower proportional loss rates. A linear regression model on the PLR shows a decreasing trend as production volume increases. Such dependency on production has been observed in several prior measurement campaigns in Canada and the US [29], [50].

Figure S4(b) shows the energy-based proportional loss rate, taking into consideration both oil and gas production volume. Overall, the energy-based PLR is estimated to be $2.6 \%$, with a gas and oil site PLR $_{\mathrm{e}}$ being $1.9 \%$ and $3 \%$, respectively. 

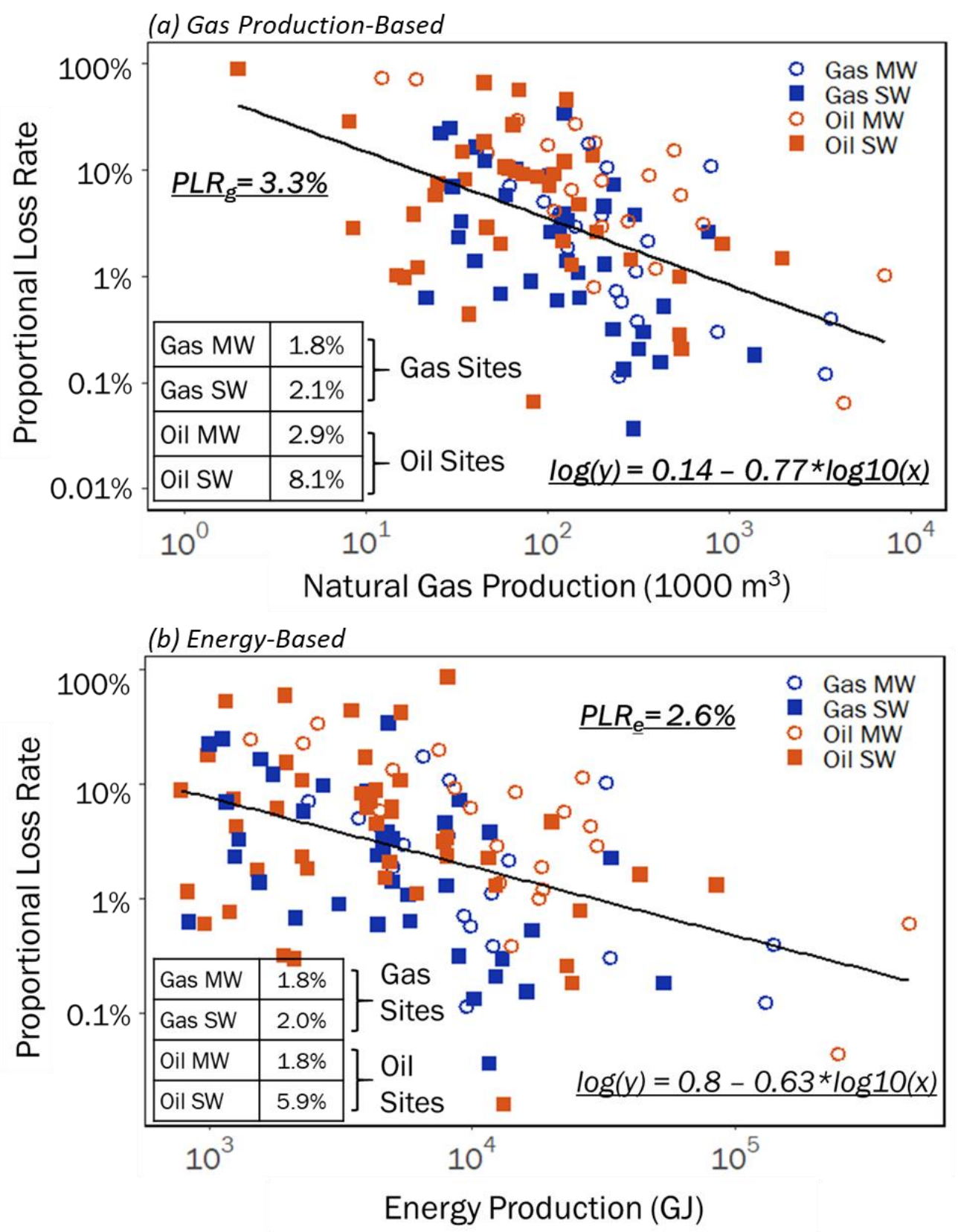

1009 Figure S4: (a) Gas production-based and (b) energy-based proportional loss rates of 1010 sites, disaggregated by site types (Oil MW and Oil MWPro are combined into Oil MW). 1011 Sites with no entries on Petrinex are removed from analysis. Black solid lines show linear 1012 regression fits to log production data.

\section{S.6 Site-level reported venting}

1014 Besides gas and oil production volumes, operators are also required to report on some 1015 vent emission volumes to Petrinex. Here we compare the rankings of reported venting 1016 and measured emissions to evaluate if reported venting is a good indicator of methane 1017 emissions. 58 sites from the fall 2018 and 52 sites from the fall 2019 surveys have 
1018

1019

1020

1021

1022

1023

1024

1025

1026

1027

1028

1029

1030

1031

1032

reported venting emissions on Petrinex, respectively. We ranked these sites from the largest to the smallest by 1) reported venting and 2) measured emissions. As shown in Figure $\mathrm{S} 5$, the $\mathrm{X}$-axis is the ranking by measured emissions and the $\mathrm{y}$-axis is the ranking by reported venting. If a site's ranking from reported venting equals its ranking from measured emissions, the data point will lie on the $y=x$ diagonal line. We further analyzed the probability of reported venting ranks falling within $25 \%$ of measured emission ranks, as indicated by the area between the $y=0.75 \mathrm{x}$ and $\mathrm{y}=1.25 \mathrm{x}$ lines. $24 \%$ of sites (14 out of 58) in fall 2018 survey have reported venting ranks within $25 \%$ of measured emissions. $27 \%$ of sites (14 out of 52) in fall 2019 survey have reported venting ranks within $25 \%$ of measured emissions. However, overall, there is no correlation between reporting venting rank and measured emission rank, indicating that reported venting may not be a good indicator of overall emissions. This finding was also previously observed in a top-down study in the region that measured significantly higher emissions than reported vent volumes [12].
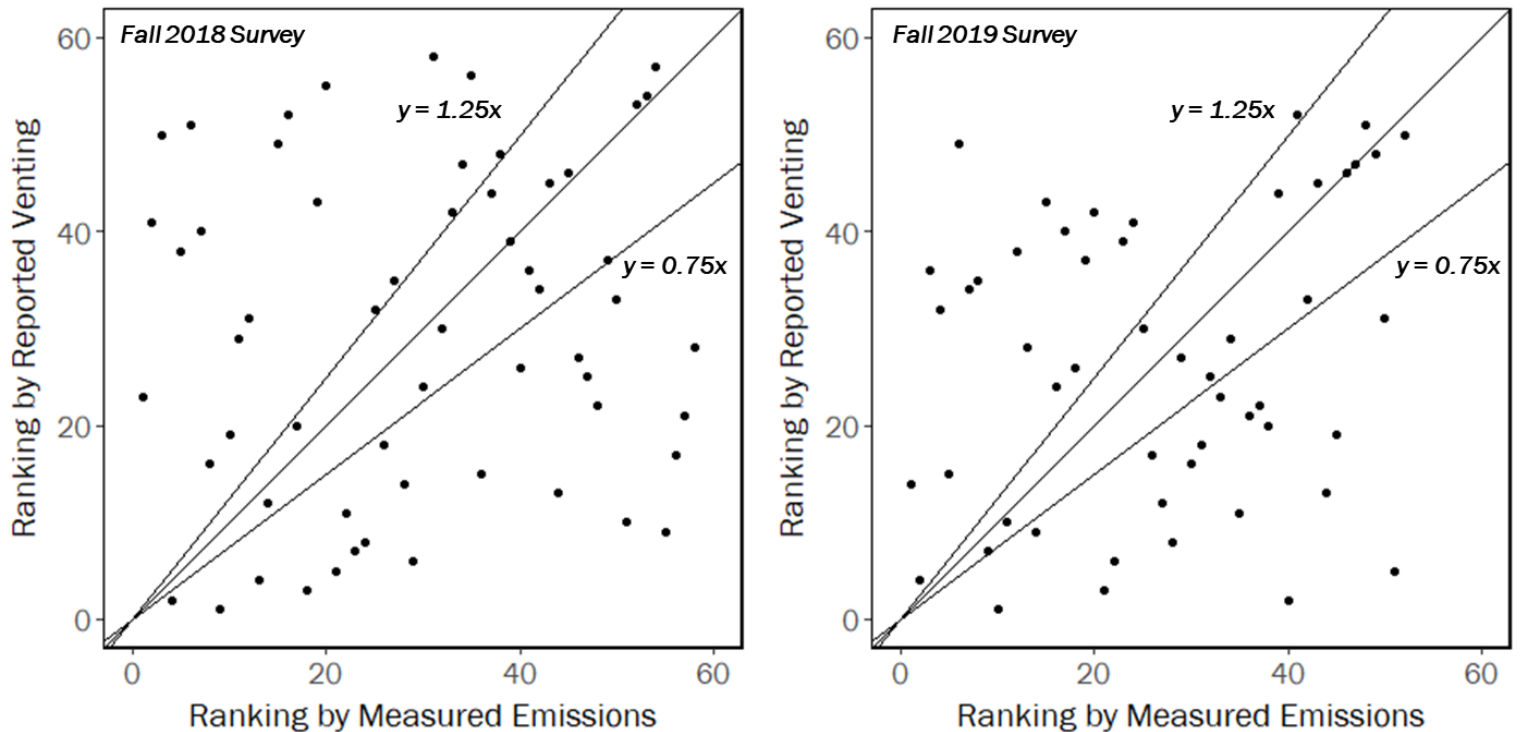

1033

1034

1035

1036

1037

1038

1039

1040

1041

1042

1043

1044

1045

Figure S5: Site ranking by measured emissions and reported venting. The $x$-axis shows the ranking of sites by measured emissions and $y$-axis shows the ranking of sites by reported venting. The diagonal line is $y=x$. The $y=0.75 x$ line and $y=1.25 x$ line stand for $25 \%$ range of ranking by measured emissions.

\section{S.7 Operator differences in emissions}

Bottom-up methane studies routinely face the "coalition of the willing" challenge, where operators with better emissions management are more likely to volunteer in research projects measuring methane emissions. However, because our study was designed to be fully random and anonymized, we effectively avoided the "coalition of the willing" challenge and thus, collected a unique dataset to understand the emissions difference across operators. This is crucial because regulations are applied to all operators uniformly with the assumption that emissions vary minimally across operators. Consequently, validating such an assumption can provide critical insights to help improve the cost 
effectiveness of methane regulations. There are several factors that may explain the variance in operators' emissions management, including but not limited to voluntary maintenance protocol, asset portfolio, infrastructure age, and production volumes.

A total of 18 operators participated in our study. Although some operators had few sites $(1-3)$ surveyed as part of this study and will not be statistically representative of emissions across their assets, comparison across operators provide valuable insights. Figure S6 is a boxplot of total emissions associated with each operator. The solid black line on each box represents the median of site-level emissions. The red diamond on each box represents the mean of site-level emissions. Operators are sorted by their mean emissions, shown by the red diamonds. We make several important observations. First, the median emissions across all operators are less than $100 \mathrm{~kg} \mathrm{CH}_{4} / \mathrm{d} / \mathrm{site}$, indicating that a large fraction of sites under an operator's portfolio have low emissions. Second, we observe an order of magnitude variation in average methane emissions, from about $20 \mathrm{~kg}$ $\mathrm{CH}_{4} / \mathrm{d} /$ site for operator $\mathrm{H}$ to about $270 \mathrm{~kg} \mathrm{CH}_{4} / \mathrm{d} /$ site for operator $\mathrm{F}$. This wide range in average emissions when median emissions are similar across operators indicates the role of a small number of high-emitting sites in an operator's asset portfolio that contributes to a majority of emissions. Finding these high-emitting sites could significantly reduce overall emissions. Third, operators with more oil sites exhibit higher emissions, on average, than operators with more gas sites. Among the three operators with the highest average emissions, $61 \%$ of the total emissions come from oil sites. Fourth, the emission distribution across operators is also skewed. The top $20 \%$ of operators $(n=4)$ with high average emissions contribute to $45 \%$ of total emissions - in total, these 4 operators account for $28 \%$ of total sites in the study. Fifth, emissions reductions across operators are also skewed. Three of the four highest average emitting operators in August 2018 reduced average site-level emissions by $59 \%, 78 \%$, and $55 \%$, respectively, contributing to a majority of the overall emissions reductions. This observation empirically confirms prior modeling studies - sites with high baseline or initial emissions also have the highest potential to reduce emissions [18]. 


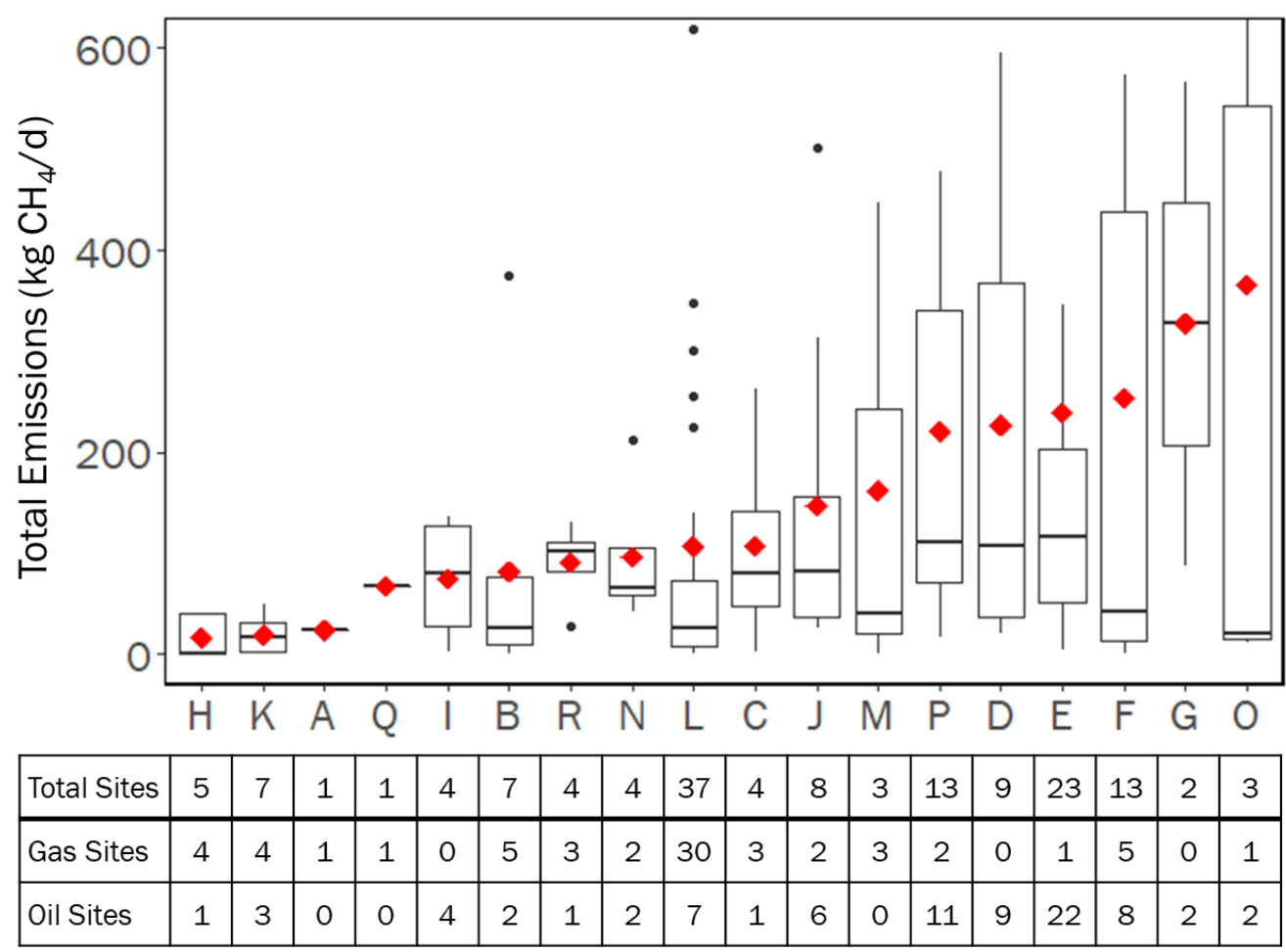

1075

1076

1077

1078

1079

1080

1081

1082

1083

1084

1085

1086

1087

1088

1089

1090

1091

1092

1093

Figure S6: Distribution of site-level emissions across operators. The $x$-axis is the anonymized operators and y-axis is the emissions per site. The solid black line on each box represents the median of site-level emissions. The red diamond on each box represents the mean of site-level emissions. The table underneath shows the distribution of oil and gas sites among operators.

\section{S.8 Impact of LDAR surveys on total emissions}

Figure S7 shows the site-level average emissions at control and treatment groups between the initial August 2018 survey and the final August 2019 survey. The corresponding change in average number of emitters is shown in the main text (Figure 5). The averages of initial site-level emissions and emitters from both 'repaired once' and 'repaired consistently' groups are higher than that from control and non-repaired groups. This is due to differences in the composition of site types in each group (Table S12). At least three quarters of the sites in the control group and not repaired treatment group are Gas SW and Oil SW, which have lower average site-level emissions and emitters. On the other hand, approximately half of the sites in repaired once and repaired consistently treatment groups are from multi-well batteries, whose average emissions and average number of emitters per site are more than double that of single wells.

Table S12: Composition of site types in control and treatment groups

\begin{tabular}{|l|c|c|c|c|c|}
\hline & Gas MW & Gas SW & Oil MW & $\begin{array}{c}\text { Oil } \\
\text { MWPro }\end{array}$ & Oil SW \\
\hline Control & 2 & 14 & 3 & 4 & 13 \\
\hline Not Repaired & 5 & 19 & 3 & 5 & 25 \\
\hline Repaired Once & 12 & 15 & 2 & 8 & 17 \\
\hline
\end{tabular}




\begin{tabular}{|l|l|l|l|l|l|}
\hline Repaired Consistently & 10 & 2 & 1 & 3 & 10 \\
\hline
\end{tabular}

The impact of repair activities on emissions is further analyzed at the site level between control and treatment groups. In Figure S7, the change in average site-level total, leak, and vent emissions are compared based on repair activities. Repaired sites show significantly more emissions reduction than non-repaired sites - the more consistent the repair, the higher the emissions reduction. Consistently repaired sites show site-level average emissions reduction of $69 \%$, as compared to the $62 \%$ from sites that are repaired at least once and 19\% from treatment sites that are not repaired. As for average leak emissions, consistently repaired sites see a reduction of $74 \%$, as compared to $65 \%$ from repaired at least once sites and 19\% from not repaired sites. Since emissions are highly skewed, reduction from large leaks $\left(>100 \mathrm{~kg} \mathrm{CH}_{4} / \mathrm{d}\right)$ can contribute disproportionately to average emissions reductions. For example, while the number of large leaks $(>100 \mathrm{~kg}$ $\left.\mathrm{CH}_{4} / \mathrm{d}\right)$ at 'not repaired' sites are similar $(\mathrm{n}=3$ vs. $\mathrm{n}=4)$ between two surveys, the average emission rate of these leaks reduced from $294 \mathrm{~kg} \mathrm{CH}_{4} / \mathrm{d}_{\text {to }} 165 \mathrm{~kg} \mathrm{CH}_{4} / \mathrm{d}$. The reduction from these large leaks contributed to $67 \%$ of total leak reduction. The $57 \%$ reduction in average leak emissions at control sites is similarly driven by reductions from large leaks (>100 $\left.\mathrm{kg} \mathrm{CH}_{4} / \mathrm{d}\right)$. Thus, even when the average number of leaks per site did not change significantly between the initial and final survey at control and 'not repaired' sites (see Figure 5 in the main text), we observe a significant reduction in leak emissions.

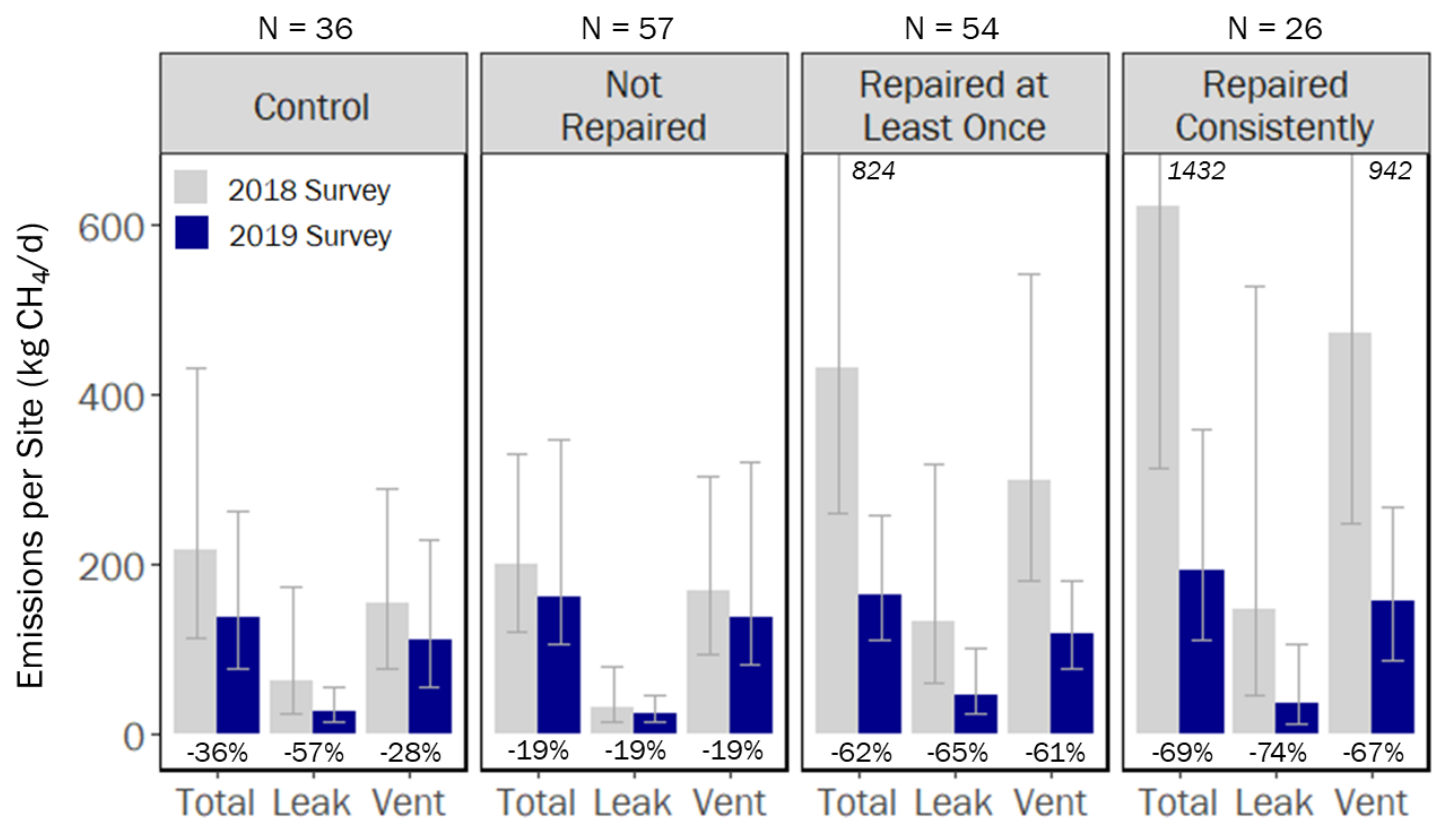

Figure S7: Site-level average emissions evolution from control and treatment group. Emissions per site are further disaggregated into leak and vent emissions. The numbers on top of the chart show the sample size of each category. One control site was repaired inadvertently and removed from the analysis. "Not Repaired" include sites that are not repaired at any temporal surveys. "Repaired at Least Once" include sites that are repaired at least once throughout temporal surveys. "Repaired Consistently" include sites that are repaired at each of the temporal surveys. The error bars represent $95 \%$ confidence interval with bootstrapping. 


\section{S.9 Study limitations}

1122 Since tracking emissions with physical tags relies on the actions of on-site operators, 1123 information on the date of repair was not consistently available across all leak tags

1124 because some operators addressed the repair but did not put down the date of repair. This 1125 made attribution challenging. Future studies on the effectiveness of LDAR surveys might 1126 consider focusing on overall emissions reduction through large-scale, site-level surveys, 1127 coupled with limited on-the-ground interviews with operators. Furthermore, such an 1128 aerial measurement is likely to avoid the issue of ambiguity in the definitions of vents 1129 and leaks across jurisdictions.

When selecting sites for our study, we divided sites equally into treatment groups with different LDAR survey frequency. However, treatment groups that require more visits are likely to miss scheduled repairs and encounter site access issues, especially in the winter. Thus, developing sampling strategies that account for higher uncertainty and lower compliance at sites with higher survey frequencies could improve the predictive power of the results.

The use of QOGI to quantify emissions was selected due to the need to measure all emissions at facilities that conventional instruments like Bacharach Hi-Flow sampler would find challenging. Other options such as tracer methods or drones do not have sufficient spatial resolution, are logistically challenging, and/or economically restrictive given the scale of the program. However, the choice of QOGI also increases uncertainty in quantification estimates compared to other approaches. While the higher uncertainty is partially mitigated by aggregating data across component and site types, future studies should consider alternative methods of quantifying component-level emissions. We also recommend more controlled release experiments to better characterize the accuracy and precision of QOGI. 


\section{Reference}

[1] R. K. Pachauri, L. Meyer, and The Core Writing Team, "Climate Change 2014 Synthesis Report," IPCC.

[2] E. Masood and J. Tollefson, "COP26 climate pledges: What scientists think so far," Nature, Nov. 2021, doi: 10.1038/d41586-021-03034-Z.

[3] Global Carbon Project, "Global Methane Budget," 2020. [Online]. Available: https://www.globalcarbonproject.org/methanebudget/20/hl-compact.htm

[4] "Methane Emissions from Oil and Gas - Analysis," IEA. https://www.iea.org/reports/methane-emissions-from-oil-and-gas (accessed Dec. 09, 2021).

[5] "Standards of Performance for New, Reconstructed, and Modified Sources and Emissions Guidelines for Existing Sources: Oil and Natural Gas Sector Climate Review," Federal Register, Nov. 15, 2021.

https://www.federalregister.gov/documents/2021/11/15/2021-24202/standards-ofperformance-for-new-reconstructed-and-modified-sources-and-emissionsguidelines-for (accessed Dec. 09, 2021).

[6] L. S. Branch, "Consolidated federal laws of canada, Regulations Respecting Reduction in the Release of Methane and Certain Volatile Organic Compounds (Upstream Oil and Gas Sector)," Jan. 01, 2020. https://lawslois.justice.gc.ca/eng/regulations/SOR-2018-66/ (accessed Mar. 09, 2021).

[7] M. Omara, M. R. Sullivan, X. Li, R. Subramanian, A. L. Robinson, and A. A. Presto, "Methane Emissions from Conventional and Unconventional Natural Gas Production Sites in the Marcellus Shale Basin," Environmental Science \& Technology, vol. 50, no. 4, pp. 2099-2107, Feb. 2016, doi: 10.1021/acs.est.5b05503.

[8] D. Zavala-Araiza et al., "Reconciling divergent estimates of oil and gas methane emissions," Proceedings of the National Academy of Sciences, p. 201522126, Dec. 2015, doi: 10.1073/pnas.1522126112.

[9] D. R. Lyon et al., "Constructing a Spatially Resolved Methane Emission Inventory for the Barnett Shale Region," Environmental Science \& Technology, vol. 49, no. 13, pp. 8147-8157, Jul. 2015, doi: 10.1021/es506359c.

[10] T. N. Lavoie et al., "Aircraft-Based Measurements of Point Source Methane Emissions in the Barnett Shale Basin," Environmental Science \& Technology, vol. 49, no. 13, pp. 7904-7913, Jul. 2015, doi: 10.1021/acs.est.5b00410.

[11] E. Chan et al., "Eight-Year Estimates of Methane Emissions from Oil and Gas Operations in Western Canada Are Nearly Twice Those Reported in Inventories," Environmental Science \& Technology, vol. 54, no. 23, pp. 14899-14909, Dec. 2020, doi: 10.1021/acs.est.0c04117.

[12] M. R. Johnson, D. R. Tyner, S. Conley, S. Schwietzke, and D. Zavala-Araiza, "Comparisons of Airborne Measurements and Inventory Estimates of Methane Emissions in the Alberta Upstream Oil and Gas Sector," Environ. Sci. Technol., vol. 51, no. 21, pp. 13008-13017, Nov. 2017, doi: 10.1021/acs.est.7b03525.

[13] D. Zavala-Araiza et al., "Methane emissions from oil and gas production sites in Alberta, Canada," Elem Sci Anth, vol. 6, no. 1, p. 27, Mar. 2018, doi: 10.1525/elementa.284. 
[14] D. Zavala-Araiza et al., "Toward a Functional Definition of Methane SuperEmitters: Application to Natural Gas Production Sites," Environmental Science \& Technology, vol. 49, no. 13, pp. 8167-8174, Jul. 2015, doi: 10.1021/acs.est.5b00133.

[15] A. R. Brandt et al., "Methane Leaks from North American Natural Gas Systems," Science, vol. 343, no. 6172, pp. 733-735, Feb. 2014, doi: 10.1126/science. 1247045.

[16] R. M. Duren et al., "California's methane super-emitters," Nature, vol. 575, no. 7781, pp. 180-184, Nov. 2019, doi: 10.1038/s41586-019-1720-3.

[17] A. R. Brandt, G. A. Heath, and D. Cooley, "Methane Leaks from Natural Gas Systems Follow Extreme Distributions," Environ. Sci. Technol., vol. 50, no. 22, pp. 12512-12520, Nov. 2016, doi: 10.1021/acs.est.6b04303.

[18] A. P. Ravikumar and A. R. Brandt, "Designing better methane mitigation policies: the challenge of distributed small sources in the natural gas sector," Environmental Research Letters, vol. 12, no. 4, p. 044023, Apr. 2017, doi: 10.1088/17489326/aa6791.

[19] A. M. Robertson et al., "Variation in Methane Emission Rates from Well Pads in Four Oil and Gas Basins with Contrasting Production Volumes and Compositions," Environmental Science \& Technology, vol. 51, no. 15, pp. 8832-8840, Aug. 2017, doi: 10.1021/acs.est.7b00571.

[20] H. L. Brantley, E. D. Thoma, W. C. Squier, B. B. Guven, and D. Lyon, “Assessment of Methane Emissions from Oil and Gas Production Pads using Mobile Measurements," Environmental Science \& Technology, vol. 48, no. 24, pp. 1450814515, Dec. 2014, doi: 10.1021/es503070q.

[21] D. Zavala-Araiza et al., "Super-emitters in natural gas infrastructure are caused by abnormal process conditions," Nature Communications, vol. 8, no. 1, Apr. 2017, doi: $10.1038 /$ ncomms 14012 .

[22] D. R. Caulton et al., "Importance of Superemitter Natural Gas Well Pads in the Marcellus Shale," Environmental Science \& Technology, vol. 53, no. 9, pp. 47474754, May 2019, doi: 10.1021/acs.est.8b06965.

[23] E. Atherton et al., "Mobile measurement of methane emissions from natural gas developments in northeastern British Columbia, Canada," Atmospheric Chemistry and Physics, vol. 17, no. 20, pp. 12405-12420, Oct. 2017, doi: 10.5194/acp-1712405-2017.

[24] J. Baillie et al., "Methane emissions from conventional and unconventional oil and gas production sites in southeastern Saskatchewan, Canada," Environmental Research Communications, vol. 1, no. 1, p. 011003, Feb. 2019, doi: 10.1088/25157620/ab01f2.

[25] T. A. Fox, T. E. Barchyn, D. Risk, A. P. Ravikumar, and C. H. Hugenholtz, “A review of close-range and screening technologies for mitigating fugitive methane emissions in upstream oil and gas," Environmental Research Letters, vol. 14, no. 5, p. 053002, Apr. 2019, doi: 10.1088/1748-9326/ab0cc3.

[26] F. J. Cardoso-Saldaña and D. T. Allen, "Projecting the Temporal Evolution of Methane Emissions from Oil and Gas Production Sites," Environ. Sci. Technol., vol. 54, no. 22, pp. 14172-14181, Nov. 2020, doi: 10.1021/acs.est.0c03049.

[27] J. G. Englander, A. R. Brandt, S. Conley, D. R. Lyon, and R. B. Jackson, “Aerial Interyear Comparison and Quantification of Methane Emissions Persistence in the 
Bakken Formation of North Dakota, USA," Environmental Science \& Technology, vol. 52, no. 15, pp. 8947-8953, Aug. 2018, doi: 10.1021/acs.est.8b01665.

[28] T. L. Vaughn et al., "Temporal variability largely explains top-down/bottom-up difference in methane emission estimates from a natural gas production region," Proc Natl Acad Sci USA, vol. 115, no. 46, pp. 11712-11717, Nov. 2018, doi: 10.1073/pnas.1805687115.

[29] A. P. Ravikumar et al., "Repeated leak detection and repair surveys reduce methane emissions over scale of years," Environmental Research Letters, Jan. 2020, doi: 10.1088/1748-9326/ab6ae1.

[30] Petrinex, "Conventional Volumetric Data." [Online]. Available: https://www.petrinex.ca/PD/Pages/APD.aspx

[31] AER, "Directive 017." May 12, 2020.

[32] "FLIR GFx320 OGI Camera for Hazardous Locations | FLIR Systems." https://www.flir.com/products/gfx320/ (accessed Mar. 09, 2021).

[33] "Quantitative Optical Gas Imaging System | FLIR Systems." https://www.flir.com/products/flir-ql320/ (accessed Mar. 09, 2021).

[34] Colorado Air Quality Control Commission, "Regulation Number 7: Controol of ozone via ozone precursors and control of hydrocarbons via oil and gas emissions 5 CCR 1001-9."

[35] O. US EPA, "Greenhouse Gas Reporting Program (GHGRP)," US EPA, Jun. 10, 2014. https://www.epa.gov/ghgreporting (accessed Mar. 09, 2021).

[36] T. Howard, T. W. Ferrara, and A. Townsend-Small, "Sensor transition failure in the high flow sampler: Implications for methane emission inventories of natural gas infrastructure," Journal of the Air \& Waste Management Association, vol. 65, no. 7, pp. 856-862, Jul. 2015, doi: 10.1080/10962247.2015.1025925.

[37] R. A. Alvarez, D. R. Lyon, A. J. Marchese, A. L. Robinson, and S. P. Hamburg, "Possible malfunction in widely used methane sampler deserves attention but poses limited implications for supply chain emission estimates," p. 9.

[38] J. I. Connolly, R. A. Robinson, and T. D. Gardiner, "Assessment of the Bacharach Hi FlowÒ Sampler characteristics and potential failure modes when measuring methane emissions," p. 8, 2019.

[39] D. Zimmerle et al., "Methane Emissions from Gathering Compressor Stations in the U.S.," Environ. Sci. Technol., vol. 54, no. 12, pp. 7552-7561, Jun. 2020, doi: 10.1021/acs.est.0c00516.

[40] D. Zimmerle, T. Vaughn, C. Bell, K. Bennett, P. Deshmukh, and E. Thoma, "Detection Limits of Optical Gas Imaging for Natural Gas Leak Detection in Realistic Controlled Conditions," Environ. Sci. Technol., vol. 54, no. 18, pp. 1150611514, Sep. 2020, doi: 10.1021/acs.est.0c01285.

[41] Environment and Climate Change Canada, "Regulations Respecting Reduction in the Release of Methane and Certain Volatile Organic Compounds (Upstream Oil and Gas Sector)." Koninklijke Brill NV. doi: 10.1163/9789004322714_cclc_20170024-002.

[42] C. Frankenberg et al., "Airborne methane remote measurements reveal heavy-tail flux distribution in Four Corners region," Proceedings of the National Academy of Sciences, vol. 113, no. 35, pp. 9734-9739, Aug. 2016, doi: 10.1073/pnas.1605617113. 
[43] D. R. Lyon, R. A. Alvarez, D. Zavala-Araiza, A. R. Brandt, R. B. Jackson, and S. P. Hamburg, "Aerial Surveys of Elevated Hydrocarbon Emissions from Oil and Gas Production Sites," Environmental Science \& Technology, vol. 50, no. 9, pp. 48774886, May 2016, doi: 10.1021/acs.est.6b00705.

[44] S. N. Lyman, T. Tran, M. L. Mansfield, and A. P. Ravikumar, "Aerial and groundbased optical gas imaging survey of Uinta Basin oil and gas wells," Elem Sci Anth, vol. 7, no. 1, p. 43, Nov. 2019, doi: 10.1525/elementa.381.

[45] A. P. Ravikumar, J. Wang, M. McGuire, C. S. Bell, D. Zimmerle, and A. R. Brandt, “'Good versus Good Enough?' Empirical Tests of Methane Leak Detection Sensitivity of a Commercial Infrared Camera," Environmental Science \& Technology, vol. 52, no. 4, pp. 2368-2374, Feb. 2018, doi: 10.1021/acs.est.7b04945.

[46] Y. Zhang et al., "Quantifying methane emissions from the largest oil-producing basin in the United States from space," Science Advances, vol. 6, no. 17, p. eaaz5120, Apr. 2020, doi: 10.1126/sciadv.aaz5120.

[47] X. Lan, R. Talbot, P. Laine, and A. Torres, "Characterizing Fugitive Methane Emissions in the Barnett Shale Area Using a Mobile Laboratory," Environ. Sci. Technol., vol. 49, no. 13, pp. 8139-8146, Jul. 2015, doi: 10.1021/es5063055.

[48] Natural Resources Canada, "Energy Fact Book 2016 - 2017."

[49] J. Peischl et al., "Quantifying atmospheric methane emissions from oil and natural gas production in the Bakken shale region of North Dakota: $\mathrm{CH}_{4}$ Emissions From the Bakken," Journal of Geophysical Research: Atmospheres, vol. 121, no. 10, pp. 6101-6111, May 2016, doi: 10.1002/2015JD024631.

[50] M. Omara et al., "Methane Emissions from Natural Gas Production Sites in the United States: Data Synthesis and National Estimate," Environmental Science \& Technology, vol. 52, no. 21, pp. 12915-12925, Nov. 2018, doi: $10.1021 /$ acs.est.8b03535. 